\title{
Radiologia de Tecnologia Digital aplicada à pintura: avaliação da qualidade de imagens obtidas em sistemas clínicos de Radiologia
}

\author{
Beatriz Barros $^{1 *}$ (D) Maria Margarida Ribeiro ${ }^{2,3,4}$ (D) Matilde Martins ${ }^{5}$, Diana de Almeida Ramos ${ }^{6}$, António Candeias ${ }^{7,8}$ \\ 'Imagens Médicas Integradas - Affidea, Lisboa, Portugal; \\ ${ }^{2}$ Área disciplinar de Radiologia - Escola Superior de Tecnologia da Saúde de Lisboa do Instituto Politécnico de Lisboa, Lisboa, Portugal; \\ ${ }_{3}^{3}$ Instituto Superior de Engenharia de Lisboa do Instituto Politécnico de Lisboa, Lisboa, Portugal; \\ ${ }^{4}$ Centro de Investigação em Saúde e Tecnologia H\&TRC (Health Technology Research Center), Lisboa, Portugal; \\ ${ }^{5}$ Fine Arts da Escola Hochschule für Gestaltung und Kunst FHNW, Basel, Suiça; \\ ${ }^{6}$ Faculdade de Belas Artes da Universidade de Lisboa, Lisboa, Portugal; \\ 'Laboratório de Conservação e Restauro José de Figueiredo do Instituto dos Museus e da Conservação, Lisboa, Portugal; \\ ${ }^{8}$ Centro de Investigação HERCULES - Laboratório HERCULES - Herança Cultural, Estudos e Salvaguarda, Évora, Portugal. \\ * $\square$ beatrizcr-barros@hotmail.com
}

Recebido em: 16 abril 2020; Revisto em: 15 janeiro 2021; Aceite em: 20 janeiro 2021

\begin{abstract}
Resumo
Introdução: Os exames de área têm uma grande relevância no estudo das obras de arte. Os laboratórios dedicados a este fim são escassos e empregam profissionais sem conhecimento específico em manipulação de radiações ionizantes. Desconhece-se em que medida, em Portugal, os centros Radiológicos clínicos poderiam conferir valor acrescentado à Radiografia Digital Clínica aplicada à pintura, de forma a expandir a sua área de atuação potenciando sinergias entre as duas áreas. Objetivos: Pretendeu-se analisar uma possível aplicabilidade, à pintura, dos sistemas de Radiologia Digital (CR e DR), utilizados na clínica, através da avaliação da variável "qualidade de imagem radiográfica", dado que os sistemas radiológicos clínicos, com detetores de conversão indireta ou direta de diferentes energias e fotodetetores do sinal elétrico, apresentam significativas melhorias nos padrões imagiológicos. Material e Métodos: Adquiriramse 21 radiografias através da exposição de três pinturas em três sistemas radiológicos distintos com ênfase nos parâmetros de exposição (diferença de potencial $(\mathrm{kV})$ e intensidade de corrente $(\mathrm{mAs})$ ). As obras que constituíram a amostra apresentavam técnicas, materiais e composições diferentes, e selecionadas por um museólogo. A qualidade das radiografias foi operacionalizada pelas dimensões de análise: preservação do suporte; distinção dos detalhes; contraste; definição de contornos; processo criativo e técnico e componentes/materiais. Quatro observadores (2 especialistas em imagem médica e 2 em arte), em condições de independência, avaliaram as radiografias adquiridas segundo uma escala do tipo Likert de 4 pontos. As dimensões de análise foram organizadas em 11 critérios e as condições de observação das radiografias foram standardizadas para exibição em monitor GeChic 1503H de 15,6". Resultados: As imagens mais pontuadas foram obtidas com o sistema de Radiografia Computorizada (moda: 3) que, na opinião dos observadores, proporcionou melhor visualização dos critérios de análise definidos anteriormente. Os resultados foram apresentados com base na estatística descritiva e variáveis categóricas discretas, agrupadas em classes modais. Conclusões: A Radiografia digital clínica, sobretudo a Computorizada (CR), aplicada à pintura permitiu evidenciar qualidade de imagem, podendo a sua utilização contribuir para a conservação, restauro, validação, estudo analítico, datação e autenticação das obras de arte.
\end{abstract}

Palavras-chave: Achados; radiologia convencional; pintura; sistemas radiológicos; qualidade de imagem.

\section{INTRODUÇÃo}

A realização de radiografias a obras de arte apresenta bastante relevância para a conservação e restauro destas assim como para a sua investigação e incorporação museológica. A radiografia, a fotografia, a observação por radiação ultravioleta e a observação por radiação infravermelha aplicados à pintura estão incluídas nos exames de área possibilitando um estudo mais generalizado e permitindo uma orientação para exames mais específicos, caso estes se justifiquem. Os exames pontuais incluem as análises químicas e outras técnicas analíticas que, por sua vez, são mais destrutivas para a obra. Estas análises apenas são realizadas após a execução dos exames de área, se se justificarem, com o objetivo de apurar informação adicional como por exemplo identificar a madeira que constituí a grade de suporte (Cruz-João, 1994; Cruz-João, 2002; Cruz-João, 2010).

As análises químicas e outras técnicas analíticas pretendem sobretudo garantir com segurança e precisão, por um lado que os restauros são elaborados com pigmentos ótica e quimicamente compatíveis de modo a evitar reações com pigmentos adjacentes e por outro, identificar produtos de degradação dos pigmentos e sugerir possíveis tratamentos no planeamento de conservação duma obra para que os processos de degradação possam ser travados ou revertidos. Os exames de área, no qual 
a Radiologia se inclui, para além de contribuírem também para o planeamento do processo de restauro, estão envolvidos nos estudos de peritagem e avaliação duma obra como resposta às solicitações do mercado da arte, nomeadamente a seguradoras, investidores, colecionadores, curadores, galeristas ou leiloeiros (Dewing-Thomas W et al., 1990; Alves-Rita, 2013; Gavrilov-D. et al, 2014).

Com a aplicação da técnica de radiação X na pintura tornouse possível detetar sobreposições, revelar alguns aspetos da técnica e do estilo dos autores, pôr em evidência o estado de conservação das obras ou mostrar o modo de construção dos suportes quando estes são de madeira ou outro material radioopaco. É ainda possível, revelar pinturas mais antigas, por baixo da imagem visível, descobrir aspetos estéticos, técnicos, temáticas e cronologia diferentes - os chamados "repintes" - que podem passar pela sobreposição de formas totalmente novas ou reforços de tinta realizados, em data posterior, sobre as formas originais, antes da utilização das têmperas, tintas ou outros materiais. Pode ainda detetar possíveis deteriorações na obra e respetiva extensão, (Cruz-João, 1995; Fleming-Stuart, 1986). Estes critérios são, para além de muitos outros, importantes na produção do conhecimento artístico ao longo do tempo contribuindo para alicerçar a história da arte e obter mais informação sobre os artistas.

No contexto português existem muitas obras que já foram submetidas a exames radiográficos. Entre os exemplos mais significativos encontram-se a pintura do Pentecostes, (Séc. XVI), da autoria de Vasco Fernandes, exposta no Mosteiro de Santa Cruz em Coimbra (Salgueiro-Joana et al, 2009) o Políptico de S. Vicente, do Séc. $\mathrm{XV}$, com autoria atribuída ao artista Nuno Gonçalves, exibido no Museu Nacional de Arte Antiga, em Lisboa (Cruz-João, 1994) e os Painéis do Retábulo Mor da Sé de Lamego, de Vasco Fernandes. Neste último estudo, ao nível das camadas pictóricas, detetou-se uma nova característica técnica de elevada relevância artística que apenas a radiografia teve capacidade de revelar (Salgueiro-Joana et al, 2010).

Assim como as obras portuguesas já radiografadas, também diversas pinturas internacionais têm sido estudadas com o auxílio deste método (Spring-Marika et al, 2005).

Nos estudos obtidos pela análise das radiografias, de várias obras de arte, foi possível observar vários achados responsáveis por novos rumos nas investigações encaminhando para novos pigmentos, aglutinantes, corantes, vernizes, assim como estilos e tendências, formas, traços e tons, permitindo a caracterização de materiais e técnicas empregues pelos artistas (Oliveira-Davi $F$ et al., 2013). Estes avanços técnicos, põem em evidência alguns exemplos da utilização da radiografia na pintura, desvendando segredos ao longo das várias camadas pictóricas bem como a sua supremacia face aos estudos químicos para planeamento dos processos de conservação e restauro. Esta análise pode ser extremamente valiosa para tratamentos de conservação e restauração (Rita-Alves, 2013; Kenzo-Toishi, 1965).

Esta técnica permitiu compreender que "a radiografia proporciona imagens da estrutura das pinturas essenciais quer para o diagnóstico do estado de conservação, quer para os estudos relacionados com a autoria e a autenticidade" (CruzJoão, 2010).

O presente estudo debate a seguinte problemática: Será que os atuais sistemas de Tecnologia de imagem Digital, utilizados na clínica, poderão ser adaptados à pintura, produzindo imagens com qualidade segundo critérios de aceitabilidade em termos da resposta a aspetos de conservação, restauro ou de peritagem?

\subsection{A RADIOGRAFIA NA PINTURA AO LONGO DA HISTÓRIA}

Em 1896, um ano após a descoberta da radiação $X$ foram efetuados, por W. König, em Frankfurt e por A. Töpler em Dresden, estudos de pinturas através desta nova descoberta. Menos de um ano após, Eder e Valenta (Vienenses) trabalharam artisticamente radiografias de 15 animais entre os quais a cobra esculápia que mais tarde veio a ser associada ao Deus Grego da Medicina (Marinković-Slobodan, 2012).

Alexander Faber, em Weimar, iniciou de forma sistemática o estudo de pinturas por radiação X, em 1913, e na Europa também foram surgindo várias iniciativas semelhantes às anteriores, como por exemplo durante a I Guerra Mundial, René LedouxLebart, Gabriel Goulinat, Alex Dauvilliers e M. Cailleux, utilizando um equipamento de radiografia móvel, pertencente ao exército, realizaram a primeira radiografia de uma pintura em França (Cruz-João, 2010).

Em Portugal, os primeiros estudos radiológicos aplicados a pinturas foram realizados em 1923 a nível particular por Carlos Bonvalot, resultante de um restauro efetuado a quatro pinturas do Séc. XVI provenientes da Igreja da Nossa Senhora da Assunção, em Cascais. Em 1928, Roberto de Carvalho e Pedro Vitorino iniciaram o estudo de pinturas na cidade do Porto, com o auxílio da radiografia, desenvolvendo trabalhos no Museu Municipal do Porto e, mais tarde, no Museu de Lamego e Museu de Aveiro. No decorrer das investigações da Santíssima Trindade, Roberto de Carvalho e Pedro Vitorino, médicos radiologistas, foram proibidos de realizar radiografias a pinturas com a justificação de que a radiação $X$ poderia causar danos às obras analisadas. A questão dos estragos nas telas radiografadas ganhou relevância em toda a Europa na década de 30, levando a que diversos museus proibissem tal método, entre os quais o Museu Staatlichen Museen, de Berlim (Cruz-João, 2010) (Cruz-João, 1994) (CruzJoão, 1995). Por tal motivo houve um interregno nas descrições bibliográficas referentes a esta prática.

Numa fase inicial, as recolhas radiográficas no campo artístico foram sempre realizadas com equipamentos destinados à aplicação médica, contudo, devido à importância crescente e comprovada da utilidade da radiação $X$, alguns museus começaram a adquirir equipamentos específicos para este tipo de estudos. Um dos primeiros foi, em 1924, o Museu Bayerische Staatsgemäldesammlungen, em Munique. Em 1926 seguiramse os Museu do Louvre, Museo Nazionali di Capodimonte, de Nápoles, o Fogg Art Museum, em Harvard, em 1934, a National Gallery, em Londres e em 1936 o Museu Nacional de Arte Antiga, em Lisboa (Cruz-João, 2010) (Cruz-João, 1995).

Em 1982, quando surgiu a radiografia digital, no estudo da pintura, não houve desenvolvimentos sobre esta nova tecnologia de aquisição de imagem (Cruz-João, 2010) (Cruz-João, 1995). A técnica começou mais tarde a ser aplicada de forma promissora e surgem, então, relatos da utilização da radiografia digital, como grande vantagem para a pintura, através da utilização de amplas faixas de energias de raios- $X$, ajustando 
o detetor à energia utilizada (James-A. Everette et al, 1982). A radiografia digital na pintura usa detetores de matriz do tipo de foto estimulação do semicondutor, sendo o silício amorfo (a-Si) considerado o melhor material para deteção digital de radiação $X$ na pintura. As vantagens dos detetores digitais é que incluem uma ampla faixa dinâmica, rápida aquisição e apresentação de imagens, poucos gastos com consumíveis e possibilidade de aplicação de algoritmos de processamento digital. Entre as limitações destes sistemas digitais está a resolução, problema que tem vindo a decrescer com melhor resolução dos detetores digitais disponíveis comercialmente e também a maior possibilidade de manipulação na fase de pós-processamento (Gavrilov-D. et al, 2014). Essa limitação pode ser transformada numa vantagem quando há necessidade de inclusão de algoritmos adaptativos. Para maximização da evidência das camadas pictóricas, aumento do brilho da camada de fundo ou redução de artefactos, técnicas de exposição prolongadas ou abordagem obliquada da superfície da pintura podem ser utilizadas. Calza-Cristiane et al. revelaram, em 2010, que a radiografia computorizada por IP aplicada aos estudos de "Giovéntú" de Eliseu Visconti, revelou na textura da tela, pequenas regiões de fissuras, o uso do branco de chumbo e uma composição oculta (pentimentos ou repinte) sob a pintura principal (Calza-Cristiane et al., 2010). Em 2011, Emandi-loan et al concluíram que métodos de investigação não destrutivos baseados em radiação $X$, como a radiografia digital e a tomografia computorizada, se mostraram muito úteis não só na avaliação do património cultural, mas também nas atividades de restauro e conservação, fornecendo uma infinidade de detalhes microestruturais em relação à diversidade de obras de arte estudadas (Emandi-loan et al., 2011).

Atualmente, no Laboratório José de Figueiredo (DireçãoGeral do Património Cultural - DGPC), existe um equipamento digital portátil usado para o trabalho de campo. O Laboratório possuí também uma ampola de radiação contínua que permite selecionar as energias, tendo uma variação na diferença de potencial $(\mathrm{kV})$, que vai desde os $5 \mathrm{kV}$ até aos $120 \mathrm{kV}$. Existem ainda duas ampolas de radiação pulsada, uma com diferença e potencial de $150 \mathrm{kV}$ e outra de $270 \mathrm{kV}$. Neste último caso é possível somente controlar o tempo de exposição, enquanto os restantes parâmetros são fixos.

O objetivo deste estudo foi verificar a aplicabilidade, à pintura, dos métodos e sistemas usados em Radiologia de Tecnologia Digital Clínica (CR e DR) através da avaliação da variável "qualidade de imagem radiográfica". Como objetivos específicos determinou-se explorar e otimizar o processo de aquisição da radiografia digital clínica na pintura, de modo a incrementar a existência de mais-valias entre as duas áreas.

\section{MATERIAIS E MÉTODOS}

Para cumprimento dos objetivos estabelecidos foi adotada uma metodologia faseada. A amostra é constituída por 21 imagens radiográficas obtidas a partir de 3 obras de arte. Inicialmente foram recrutadas 5 obras (4 sobre tela e 1 sobre madeira), selecionadas por uma especialista em Museologia e História de Arte e também e por uma estudante de Belas-Artes (amostra de conveniência). Das 5 pinturas iniciais, apenas 3 apresentavam uma maior variedade de composição, técnicas e fatores discricionários, que permitiriam diferenciar um maior número de características artísticas consideradas relevantes para a análise dos observadores, razão pela qual apenas 3 pinturas foram radiografadas. As duas restantes apresentavam técnicas sobreponíveis que não iriam enriquecer a amostra.

\subsection{CRITÉRIOS DE SELEÇÃO DAS OBRAS E DESCRIÇÃO DAS VARIÁVEIS EM ANÁLISE}

Os critérios de seleção das obras foi a quantidade e variabilidade de achados que a radiografia poderia representar (quanto maior a variabilidade de materiais e técnicas artísticas presentes na obra, maior são os achados radiológicos presentes na radiografia adquirida). A componente experimental consistiu na manipulação das variáveis independentes tais como a diferença de potencial (kV) e a intensidade de corrente (mAs) aplicada à ampola produtora da radiação $X$. A deteção dos achados bem como a qualidade e adequação da imagem final para o objetivo proposto constituíram as variáveis dependentes.

\subsection{DESCRIÇÃO DAS OBRAS}

A pintura 1A é composta por tela de linho com revestimento de gesso acrílico, fixada com agrafos ao bastidor de madeira de pinho (tipo de fixação mais recente). Trata-se de uma pintura com tinta de óleo e grafite tendo sido usado como solventes o óleo de linho e essência de terebintina. Possuí uma dimensão de $60 \times 50 \mathrm{~cm}$, com desenho de retrato de mulher no sentido longitudinal (Fig. 1A).

A pintura 1B é uma pintura a óleo sobre tela de linho e o bastidor também é composto por madeira de pinho. A fixação é feita com pregos de aço, o que denota uma fixação mais antiga. O solvente das tintas usado foi o white spirit. Está enquadrada na técnica mista, pois é composta por diversos materiais, entre os quais: óleo, linha/lã, papel e aguarrás. Tem uma dimensão de $50 \times 70 \mathrm{~cm}$ de maior eixo, no sentido transversal (Fig. 1B).

Tal como a $1 \mathrm{~A}$, a obra número $1 \mathrm{C}$ também é uma pintura a óleo sobre tela de linho, com revestimento de gesso acrílico, enquadrada na técnica mista por ter na sua composição diversos materiais como: pregos e cravos, adereços de papel metalizado em forma de estrela, rede e aguarrás. A fixação da grade já é feita com recurso a agrafos metálicos em madeira de pinho. A sua dimensão é de $60 \times 100 \mathrm{~cm}$ orientada no maior sentido longitudinal (Fig. 1C).

\subsection{EQUIPAMENTOS, PARÂMETROS DE EXPOSIÇÃO E METODOLOGIA DE AQUISIÇÃO DE IMAGENS}

O processo de aquisição das imagens radiográficas das pinturas selecionadas, dentro das especificidades de cada um dos equipamentos, foram replicados tanto quanto possível: a) Equipamento de Radiologia Digital de Conversão Direta Digital Radiography (DR System) - (designado por Sistema 1); b) Radiologia Computorizada de Conversão Indireta - Computed Radiography (CR System) - Sistema 2 e, por último num C) Sistema CR Computed Radiography, industrial, específico para estudos de área, utilizado no Laboratório José de Figueiredo (Sistema 3).

O Sistema 1 é um equipamento radiológico, modelo Siemens Multix Select DR e possuí as seguintes características tecnológicas: a) coluna de fixação no chão; b) o detetor é 
móvel, versátil e sem bateria, que na prática clínica, permite avaliar todas as estruturas anatómicas seja qual for a condição do doente, tendo a dimensão de $35 \times 43 \mathrm{~cm}$. O material semicondutor do detetor é o silício amorfo (a-Si), com uma matriz ativa total de $3072 \times 2560$ pixéis, para uma dimensão de pixel de $139 \mu \mathrm{m}$ e 7,75 milhões de pixéis totais. Utiliza o material cintilador - DRZ+ e tem resolução espacial, segundo a frequência de Nyquist, de 3.6 pares de linhas por milímetro (lp/ $\mathrm{mm}$ ). A deteção de eficiência quântica (DQE) é de $25 \%$ a 0.05 $\mathrm{lp} / \mathrm{mm}$, para $4 \mu \mathrm{Gy}$, e a função de modulação de transferência (MTF) de $52 \%$ a $1 \mathrm{lp} / \mathrm{mm}$ possui uma velocidade de transmissão de $(\leq 7 \mathrm{~s})$ para a imagem prévia e de $(\leq 9 \mathrm{~s})$ para a imagem completa. As imagens foram visualizadas e registadas a partir dum monitor colorido de 19 polegadas, com elevado contraste possuindo uma taxa de 2000:1 e resolução de $1280 \times 1024$. A máxima intensidade de brilho foi de $300 \mathrm{~cd} / \mathrm{m} 2$ (Siemens, 2014). Por ser um equipamento digital direto a gama de cinzentos é muito mais ampla, o que permite uma maior diferenciação entre estruturas com coeficientes de atenuação próximos; c) o gerador está acoplado à mesa, o que permite que este tipo de equipamento seja integrado qualquer que seja a dimensão da sala (Siemens, 2014). Para radiografar as telas não foi utilizado o Sistema Potter-Bucky dadas as suas propriedades de atenuação, espessura e densidade e para promover comparabilidade com os restantes Sistemas usados.
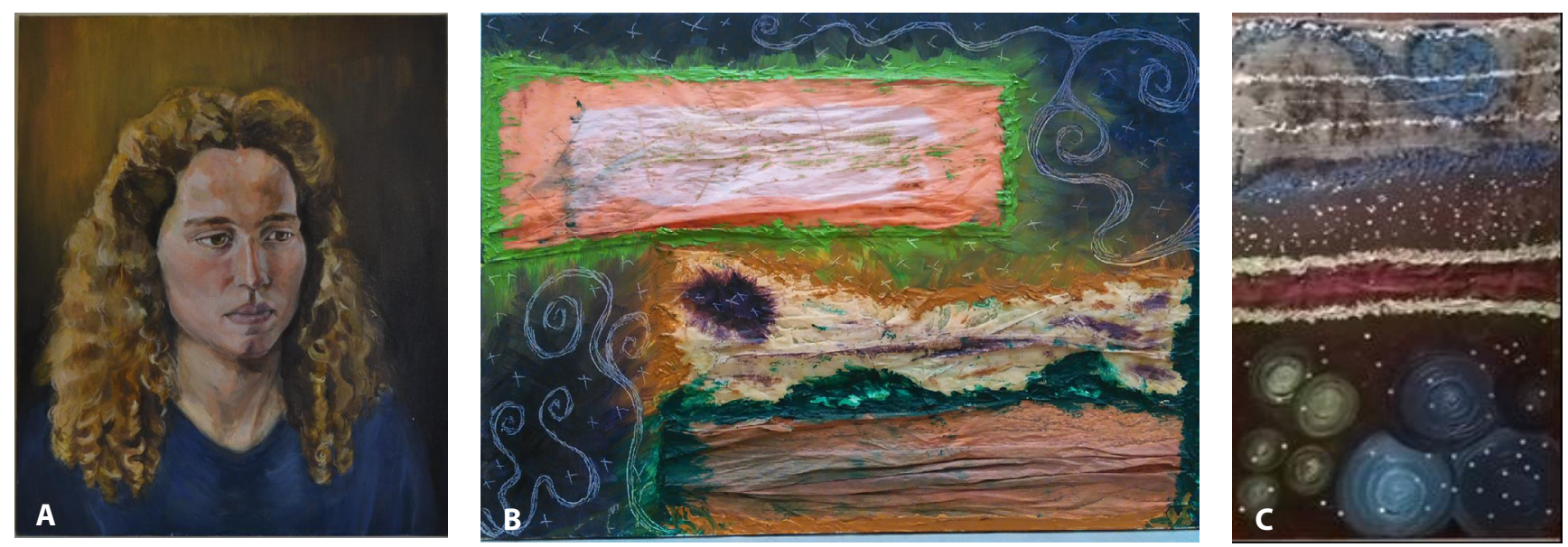

Figura 1: Pintura a óleo (A); Pintura com técnica mista (B); Pintura a óleo (C).

O Sistema 2 é um modelo Siemens Multix Pro. Como características, este equipamento apresenta: a) uma fixação no solo, possuindo uma mesa regulável; $b$ ) a grelha anti-difusora pode ser amovível. Para este equipamento existem $c$ ) detetores (Image Plate) com 3 dimensões: $18 \times 24 \mathrm{~cm} ; 24 \times 30 \mathrm{~cm}$ e $35 \times 43 \mathrm{~cm}$ (Siemens, 2010). Sendo que para este o Sistema de deteção utilizado foi o IP CR MD 4.0 DE $43 \mathrm{~cm} \times 35 \mathrm{~cm}$ contendo BaSrFBrlEu da AGFA (Agfa-Gevaert NV, Mortesel, Belgium). Trata-se dum material fotoestímulado com resolução espacial do detetor plano fotoestímulado de 10 pixéis por $\mathrm{mm}$ e a matriz de pixel $3480 \times 4248$. A base é obtida a partir duma laca à base de pó de fósforo à qual é adicionado um polímero ligante dissolvido num solvente para obter uma dispersão duma pasta branca de fósforo. Essa pasta é revestida por um substrato e os solventes são evaporados resultando uma camada seca de partículas de fósforo, unidas por um aglutinante. A matriz BaFB é um material em camadas com estrutura tetragonal. Para atingir um pico de emissão estimulada mais elevado é dopado e co-dopado com substâncias terras raras que se agregam ao material da matriz e aos aglutinantes do fósforo. Possui uma absorção na gama de energias de $20 \mathrm{keV}$ a $140 \mathrm{keV}$. A energia de conversão é elevada e estável com um decaimento na $1^{\text {a }}$. hora de 10 a $25 \%$. A luz emitida e a de estimulação são espectralmente distintas, sendo a última cerca de 105 a 109 vezes mais forte e a estimulação eficiente das cargas elétricas está na faixa do comprimento de onda entre 500 e $1.500 \mathrm{~nm}$ ajustado para um quantum de raios- $X$ de $50 \mathrm{keV}$ absorvido que cria entre 500 a 750 pares de cargas elétricas. De acordo com a potência necessária, o tamanho das partículas de fósforo é entre 2 to $15 \mu \mathrm{m}$ (LeblansPaul et al., 2011).

As radiografias também foram obtidas sem o Sistema Potter-Bucky; d) a leitura do IP é feita com recurso a um digitalizador ADC $^{\text {TM }}$ Solo ${ }^{\text {TM }}$ Digitizer da AGFA (Agfa-Gevaert NV, Mortsel, Belgium) e um Sistema NX e e) o processamento de imagem foi efetuado num Sistema NX para identificação de imagem e controlo da qualidade com Sistema MUSICA, também da marca AGFA.

O Sistema 3 adquiriu radiografias no Instituto José de Figueiredo, com a) uma ampola YXLON, modelo SMART $160 \mathrm{E} / 0,4$. Esta ampola é uma ampola industrial, com um feixe de projeção elíptica. A diferença de potencial varia entre 10$160 \mathrm{kV}$ e os $\mathrm{mA}$ variam entre 2.0-6.0. O tempo de exposição pode variar entre 1 segundo a 99 minutos. Pode ser usada como ampola portátil para trabalho de campo ou para radiografias em sala. Possuí um peso de $22 \mathrm{~kg}$ e uma altura de $616 \mathrm{~mm}$; b) o gerador é leve e de alta qualidade, por forma a corresponder a todos os trabalhos industriais (YXLON); c) os detetores utilizados, constituídos por camadas de fósforo Dürr NDT 35/43, tinham uma dimensão de $35 \times 43 \mathrm{~cm}$, sendo que, para radiografar a grade da tela 1 foi utilizado um detetor com dimensão de $18 \times 24 \mathrm{~cm}$. As radiografias foram adquiridas na Sala João Couto e a aquisição de imagens radiográficas foi feita em Sistema $\mathrm{CR}$; $d$ ) o pós-processamento foi obtido através de um scanner modelo CR 35 segundos, série X000343 (Scanna, Durr NDT, Germany) (Fig. 2), abaixo, e e) trabalhado com recurso à plataforma ScanViewer CR. 


\section{Artigos Científicos}

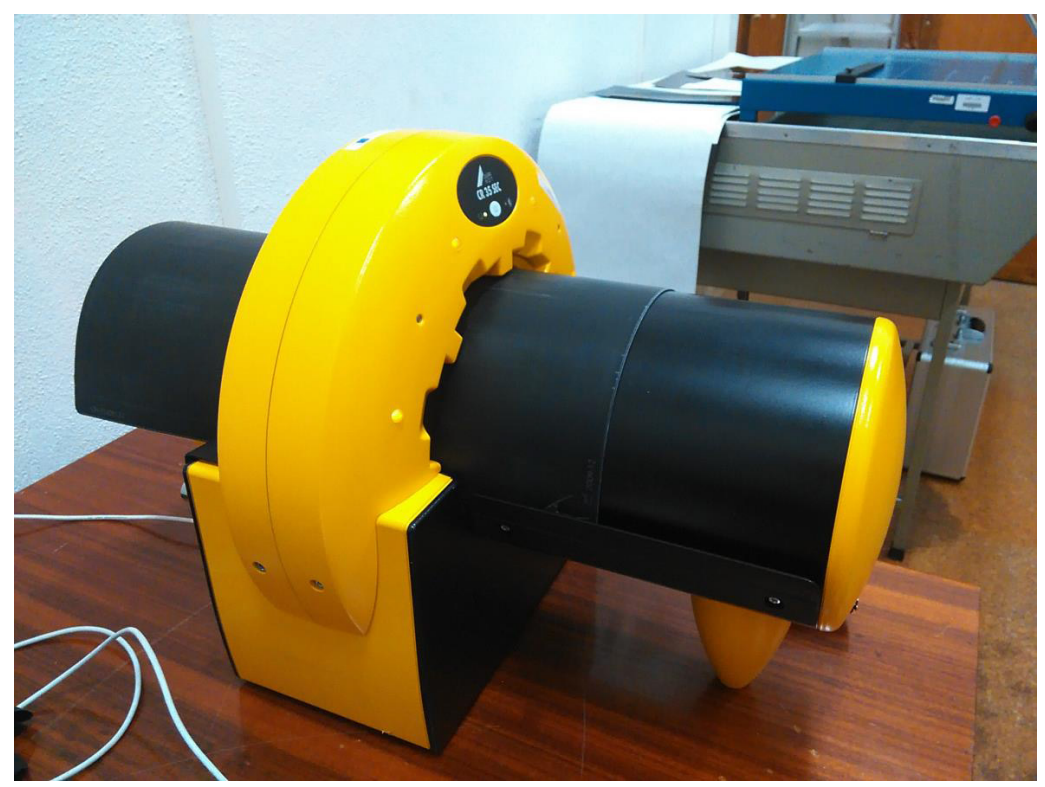

Figura 2: Scanner modelo CR 35 segundos, série X000343.

Para obter as radiografias das obras em estudo, os parâmetros de exposição utilizados nos Sistemas 1 e 2 foram os apresentados na tabela I.

No Sistema 3, foi realizada uma exposição com 16kV, $5 \mathrm{~mA}$, com um tempo de exposição de 460 segundos ( $2300 \mathrm{mAs}$ ). A distância entre a ampola e o detetor foi de $2,10 \mathrm{~m}$.

Foi-nos assegurado que todos os equipamentos tinham sido alvo da intervenção de manutenção periódica, há menos de 1 mês, quando as aquisições foram efetuadas.

Os parâmetros de exposição utilizados para a obtenção das radiografias (Tabela 1) basearam-se nos valores de referência recomendados pelo laboratório da National Gallery (PadfieldJoseph et al., 2002), tal como em outros valores de referência da radiografia digital aplicada ao estudo de Património Cultural (Oliveira-Davi F et al., 2013).

Tabela 1: Protocolo de aquisição de radiografias no equipamento DR e CR.

\begin{tabular}{|c|c|c|c|c|c|}
\hline Exposição & $\mathbf{k V}$ & $\mathbf{m A s}$ & Foco & Rendimento da ampola & DFD (m) \\
\hline 1 & 40 & 0,90 & Grosso & $80 \%$ & 1,10 \\
\hline 2 & 40 & 0,50 & Grosso & $80 \%$ & 1,10 \\
\hline 3 & 40 & 2,8 & Grosso & $80 \%$ & 1,10 \\
\hline 4 & 40 & 1,25 & Grosso & $80 \%$ & 1,10 \\
\hline
\end{tabular}

\subsection{AVALIAÇÃO DAS IMAGENS RADIOGRÁFICAS ADQUIRIDAS}

Não foi efetuado qualquer manipulação ou pós processamento de imagem afim de não contrafazer a imagem original obtida em cada um dos sistemas, bem como proceder da forma mais equitativa na avaliação das diferentes imagens. Foi apenas ajustado nível de densidade ótica para valores passíveis duma visualização correta. As imagens foram todas transferidas das estações de visualização e armazenadas num um dispositivo de armazenamento externo.

Após a aquisição de todas as radiografias compararamse as imagens obtidas nos diversos equipamentos. Para tal foi reunido um painel de quatro observadores: observador $A$ e $B$ com conhecimento em interpretação radiológica clínica e, C e D com experiência em arte e na produção de técnicas artísticas. Os quatro observadores analisaram as imagens radiográficas das 3 telas. Por forma a avaliar as imagens, foram aplicadas aos observadores as questões de forma sistemática, com opções de resposta fechada, baseadas numa escala de classificação do tipo Likert, ponderada em 4 pontos, incluindo a opção "não se aplica/não sei". A escala é do tipo crescente, ponderada e assimétrica em que o valor 1 indica "má" qualidade e o valor 4"muito boa" qualidade.

Pretendeu-se avaliar, segundo a opinião dos observadores, se os sistemas clínicos apresentam uma boa classificação de forma a poderem ser utilizados para a representação da composição artística (Ludewig-Eberhard et al., 2010; Art Intitute Chicago, 2020; Ween-Borgny et al., 2015; Tingberg-Anders et al., 2000).

As imagens foram inseridas numa plataforma para melhor observação e em proporcionar idênticas condições de visualização aos observadores. As condições de tempo, intensidade de luz e distância ao monitor foram standardizadas para todos os observadores, que efetuaram a classificação, em condições de independência. Depois de organizadas em conjuntos, as imagens foram exibidas aos observadores num monitor GeChic $1503 \mathrm{H}$ de 15,6 .

Os onze critérios de classificação foram encontram-se descriminados na tabela 2.

Em disposição lateral, cada conjunto era composto por 3 
imagens de uma mesma pintura, obtida através de cada um dos diferentes sistemas. O Sistema, origem de cada imagem, era desconhecido dos observadores. A ordem pela qual as imagens apareciam em cada conjunto foi aleatorizada para não incorrer numa tendência de padrão que pudesse influenciar a opinião dos observadores. A seleção das mesmas encontra-se representada na tabela 3.

A exposição 1 da pintura $1 \mathrm{~A}$ foi escolhida por ser referida na literatura (Oliveira-Davi $F$ et al., 2013) e por demonstrar a fixação da grade com agrafos. A exposição 4 foi selecionada, no centro da tela, pelo facto de idêntico caso ser mencionado pela National Gallery e por se observar uma área relevante para a avaliação (Padfield-Joseph et al., 2002). Quanto às radiografias adquiridas no Sistema 3, foram selecionadas para avaliação, a imagem da grade e também a radiografia onde se observa o centro da pintura.

Da pintura 1B, dividida em quatro cantos, por não permitir um estudo único da área total da tela, foram analisados o Canto Inferior Direito e o Canto Inferior Esquerdo (Padfield-Joseph et al., 2002), pois os dois cantos selecionados eram os que apresentavam uma maior diversidade de material. Juntamente a estas imagens, foram também colocadas as imagens obtidas com o Sistema 3 e com os parâmetros de exposição utilizados na aquisição de imagens deste sistema.

Quanto à obra 1C, foram analisadas todas as radiografias para todos os Sistemas obtidos na quarta exposição (PadfieldJoseph et al., 2002). Esta obra, também, foi examinada de forma fracionada pela mesma razão da obra número $1 \mathrm{~B}$.

A organização das imagens para análise obedeceu a 3 imagens por grupo totalizando 7 grupos de acordo com as combinações entre pinturas, áreas radiografadas e Sistemas, originando uma amostra submetida a avaliação de 21 radiografias.

A cada conjunto foi atribuído um código de classificação (I-VII).

Para o tratamento dos dados utilizaram-se procedimentos de estatística descritiva. Assim, foram apenas usadas medidas de tendência central e contagem frequencial e variáveis categóricas discretas, agrupadas em classes modais.

Tabela 2: Critérios de avaliação.

\begin{tabular}{|c|}
\hline Presença de sobreposições/ Repintes na Imagem \\
\hline Existência de desenho subjacente \\
\hline Pinceladas diferentes na imagem/Processo criativo e técnico da tela \\
\hline Existência de vários materiais \\
\hline Perceção do estado de conservação do suporte/grade \\
\hline Adequação da escala de cinzentos para o estudo em causa \\
\hline Nitidez dos contornos de todas as estruturas que compõem a imagem \\
\hline Adequação da relação sinal-ruído \\
\hline Adequação do contraste da imagem \\
\hline Nitidez da imagem/figura \\
\hline Observação de outros achados/comentários \\
\hline
\end{tabular}

Tabela 3: Áreas e exposições analisadas pelos observadores.

\begin{tabular}{|c|c|c|}
\hline \multirow{2}{*}{ Obra } & Exposições analisadas & Área da obra em estudo \\
\hline \multirow{2}{*}{ Pintura 1A } & Exposição 1 & Margem da obra \\
\cline { 2 - 3 } & Exposição 4 & Centro da obra \\
\hline \multirow{2}{*}{ Pintura 1B } & Exposição 4 & Canto inferior direito \\
\cline { 2 - 3 } & Exposição 4 & Canto inferior Esquerdo \\
\hline \multirow{2}{*}{ Pintura 1C } & Exposição 4 & Lado Direito \\
\cline { 2 - 3 } & Exposição 4 & Centro \\
\cline { 2 - 3 } & Exposição 4 & Lado Esquerdo \\
\cline { 2 - 3 } & &
\end{tabular}

\section{RESULTADOS}

Conjunto I (Figura 3 A-C): Representa a fixação da grade da pintura $1 \mathrm{~A}$, com agrafos.

Neste conjunto I verificou-se que somente uma pessoa referiu haver, com uma boa visualização, "repintes" na imagem
3B (adquirida no Sistema 1) e na imagem 3C (adquirida no Sistema 3), tendo ambas obtido a mesma classificação.

Também se apurou que somente um observador referiu haver um "desenho subjacente" na imagem, sendo que, para esta característica, a imagem 3A (adquirida no Sistema 2), foi a mais pontuada. 
Quanto à identificação de "pinceladas do processo criativo", a imagem 3A (adquirida no Sistema 2) foi a mais pontuada seguida da 3C (Sistema 3), tendo obtido um maior consenso entre os observadores.
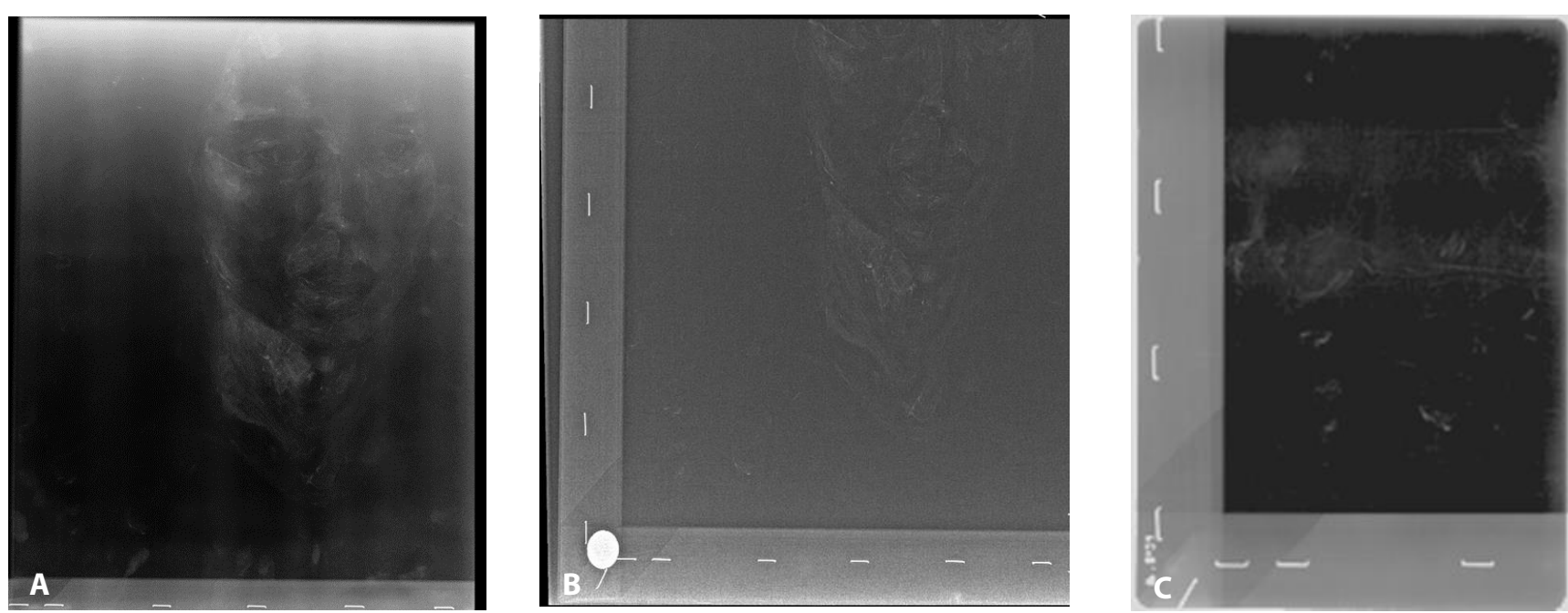

Figura 3: Sistema 2/CR (A); Sistema 1/DR (B); Sistema 3/Industrial (C).

Em relação à identificação clara de "diferentes materiais" na imagem, apenas um observador avaliou este item positivamente.

O "estado do suporte/grade" foi, na opinião dos observadores, bem visualizado em todos os Sistemas. A imagem
3A, adquirida no Sistema 2, foi a que obteve melhor pontuação quanto à "diferenciação na escala de cinzentos", "nitidez dos contornos", "relação sinal-ruído" e "adequação do contraste". Do mesmo modo, foi esta a imagem melhor classificada quanto à "nitidez da figura/imagem" reproduzida (rosto de mulher). Estes factos são observáveis na tabela 4.

Tabela 4: Classificação dos critérios de avaliação enumerados de 1 a 10 .

\begin{tabular}{|c|c|c|c|}
\hline Questões & Imagem A & Imagem B & Imagem C \\
\hline \multirow{5}{*}{$\begin{array}{l}\text { 1. Presença de sobreposições/ repintes } \\
\text { na imagem }\end{array}$} & Má: 3 & Má: 3 & Má: 3 \\
\hline & Aceitável: 1 & Aceitável: 1 & Aceitável \\
\hline & Boa & Boa & Boa \\
\hline & Muito Boa & Muito Boa & Muito Boa \\
\hline & Não sei/Não se aplica & Não sei/Não se aplica & Não sei/Não se aplica \\
\hline \multirow{5}{*}{$\begin{array}{l}\text { 2. Existência de desenho } \\
\text { subjacente }\end{array}$} & Má: 2 & Má: 2 & Má: 3 \\
\hline & Aceitável & Aceitável: 1 & Aceitável: 1 \\
\hline & Boa: 1 & Boa & Boa \\
\hline & Muito Boa & Muito Boa & Muito Boa \\
\hline & Não sei/Não se aplica: 1 & Não sei/Não se aplica: 1 & Não sei/Não se aplica:1 \\
\hline \multirow{5}{*}{$\begin{array}{l}\text { 3. Pinceladas diferentes na imagem/ } \\
\text { Processo criativo e técnico na tela }\end{array}$} & Má & Má: 1 & Má: 1 \\
\hline & Aceitável: 1 & Aceitável: 1 & Aceitável \\
\hline & Boa & Boa: 1 & Boa \\
\hline & Muito Boa: 3 & Muito Boa: 1 & Muito Boa: 2 \\
\hline & Não sei/Não se aplica & Não sei/Não se aplica & Não sei/Não se aplica: 1 \\
\hline \multirow{5}{*}{ 4.Existência de vários materiais } & Má & Má & Má \\
\hline & Aceitável & Aceitável & Aceitável \\
\hline & Boa & Boa & Boa \\
\hline & Muito Boa: 1 & Muito Boa: 1 & Muito Boa: 1 \\
\hline & Não sei/Não se aplica: 3 & Não sei/Não se aplica: 3 & Não sei/Não se aplica: 3 \\
\hline \multirow{5}{*}{$\begin{array}{l}\text { 5. Perceção do estado de conservação } \\
\text { do suporte/grade }\end{array}$} & Má & Má & Má \\
\hline & Aceitável & Aceitável & Aceitável \\
\hline & Boa & Boa & Boa \\
\hline & Muito Boa: 4 & Muito Boa: 4 & Muito Boa: 4 \\
\hline & Não sei/Não se aplica & Não sei/Não se aplica & Não sei/Não se aplica \\
\hline
\end{tabular}


Artigos Científicos

\begin{tabular}{|c|c|c|c|}
\hline \multirow{5}{*}{$\begin{array}{l}\text { 6. Adequação da escala de cinzentos } \\
\text { para o estudo em causa }\end{array}$} & Má & Má: 2 & Má: 2 \\
\hline & Aceitável: 1 & Aceitável: 2 & Aceitável \\
\hline & Boa: 1 & Boa & Boa: 1 \\
\hline & Muito Boa: 2 & Muito Boa & Muito Boa \\
\hline & Não sei/Não se aplica & Não sei/Não se aplica & Não sei/Não se aplica: 1 \\
\hline \multirow{5}{*}{$\begin{array}{l}\text { 7. Nitidez dos contornos de todas as } \\
\text { estruturas que compõem a imagem }\end{array}$} & Má & Má & Má: 1 \\
\hline & Aceitável & Aceitável: 2 & Aceitável: 1 \\
\hline & Boa: 2 & Boa & Boa: 1 \\
\hline & Muito Boa: 2 & Muito Boa: 2 & Muito Boa: 1 \\
\hline & Não sei/Não se aplica & Não sei/Não se aplica & Não sei/Não se aplica \\
\hline \multirow{5}{*}{ 8. Adequação da relação sinal-ruído } & Má & Má & Má: 1 \\
\hline & Aceitável: 1 & Aceitável: 4 & Aceitável: 2 \\
\hline & Boa: 1 & Boa & Boa: 1 \\
\hline & Muito Boa: 2 & Muito Boa & Muito Boa \\
\hline & Não sei/Não se aplica & Não sei/Não se aplica & Não sei/Não se aplica \\
\hline \multirow{5}{*}{ 9. Adequação do contraste da imagem } & Má & Má & Má: 1 \\
\hline & Aceitável & Aceitável: 4 & Aceitável \\
\hline & Boa: 2 & Boa & Boa: 3 \\
\hline & Muito Boa: 2 & Muito Boa & Muito Boa \\
\hline & Não sei/Não se aplica & Não sei/Não se aplica & Não sei/Não se aplica \\
\hline \multirow{5}{*}{ 10. Nitidez da imagem/ figura } & Má & Má & Má: 1 \\
\hline & Aceitável & Aceitável: 3 & Aceitável: 2 \\
\hline & Boa: 2 & Boa: 1 & Boa: 1 \\
\hline & Muito Boa: 2 & Muito Boa & Muito Boa \\
\hline & Não sei/Não se aplica & Não sei/Não se aplica & Não sei/Não se aplica \\
\hline
\end{tabular}

Em avaliação aberta, registou-se a partir da imagem 3A, a observação de dedadas do autor assim como a aplicação de tintas com componentes metálicas. Já a imagem 3B (Sistema 1), segundo os observadores, permitiu uma melhor observação das pinceladas de tinta e camadas de tinta subjacente, embora com menor índice de contraste.

Conjunto II (Figura 4 A-C): Representa o centro da pintura $1 \mathrm{~A}$.

No conjunto II apenas um dos observadores visualizou o efeito de sobreposição na imagem, ou "repinte", sobretudo na imagem 4B (Sistema 1), seguida da imagem 4C (adquirida no Sistema 3).
Quanto à categoria de análise "desenho subjacente" foi a imagem 4A (Sistema 2), seguida da imagem 4B (Sistema 1), as mais pontuadas. Neste conjunto de imagens os observadores não conseguiram visualizar pinceladas do processo criativo ou a presença de materiais diversificados, o que vai de encontro à composição da pintura, obtida com a técnica única de óleo sobre tela. Referindo-se ao registo e imagem sobre o estado conservação do suporte/grade, os observadores dividem-se simetricamente quanto à opinião. A avaliação da "escala de cinzentos" foi apenas razoavelmente classificada na imagem $4 \mathrm{~A}$ (Sistema 2). Na imagem 4B (Sistema 1) e na imagem 4C (Sistema 3), para a mesma característica, as pontuações foram discrepantes entre os observadores não se notando uma tendência de opinião.
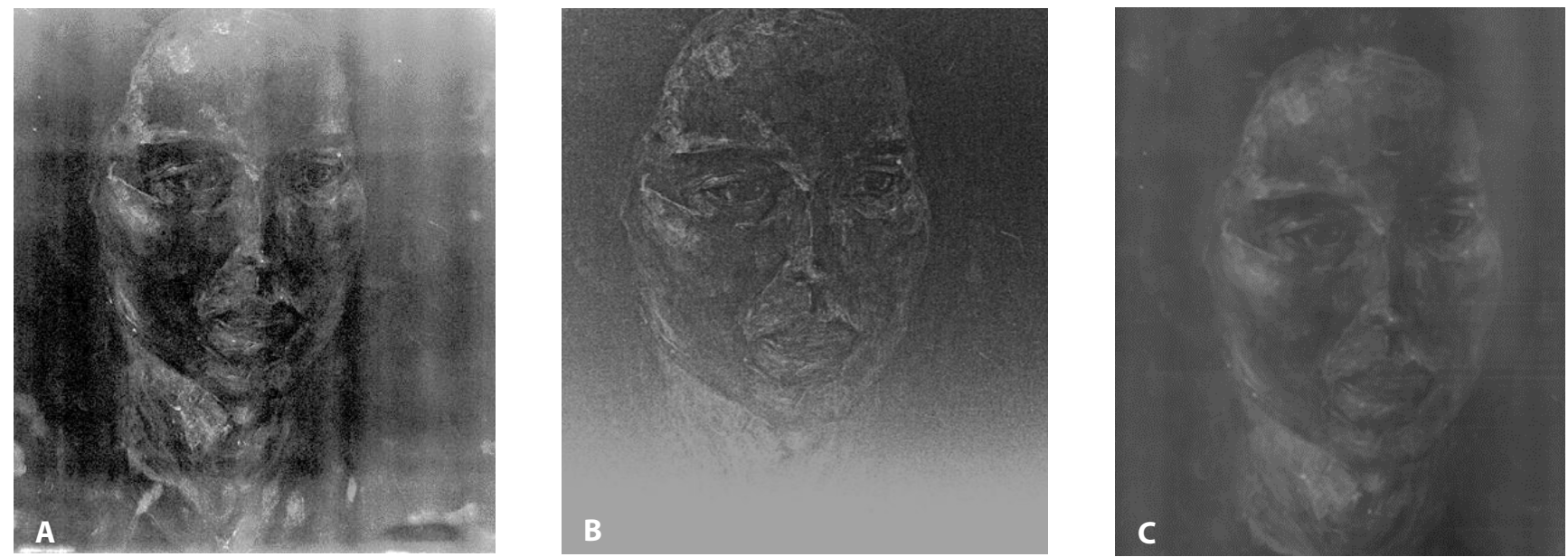

Figura 4: Sistema 2/ equipamento CR (A); Sistema 1/ equipamento DR (B); Sistema 3/ equipamento industrial (C). 
A categoria "nitidez dos contornos" neste conjunto, segue uma pontuação crescente no sentido: imagem 4A (Sistema 2); imagem 4B (Sistema 1) seguida da imagem 4C (Sistema 3). Para a avaliação "relação sinal-ruído", a sequência crescente de opinião foi: imagem 4C (Sistema 3); imagem 4A (Sistema 2) seguida da imagem 4B (adquirida no Sistema 1).

Quanto ao "contraste" e"nitidez" foi a imagem 4A (Sistema 2) que obteve melhor classificação. Os comentários gerais a este conjunto foram diferenças na "gama de cinzentos", falta de "detalhe" nas margens das imagens, "dedadas e pinceladas" na imagem 4A (Sistema 2). A imagem 4C, para os observadores tem melhor "nitidez" e "contraste" permitindo visualizar pormenores como os cabelos mais finos.
A classificação atribuída aos critérios acima descritos é possível observar na tabela 5, bem como a pontuação fornecida pelos observadores aos restantes tópicos de análise.

No que se refere aos comentários deixados pelos observadores, neste conjunto de análise, é possível destacar a identificação de diferenças no critério identificado como "gama de cinzentos", falta de detalhe nas margens das imagens, bem como a presença de "dedadas e pinceladas" na imagem 4A (Sistema 2). Foi, também, referido pelos observadores que na imagem $4 C$ há uma boa visualização de pormenores artísticos como é o caso do cabelo (pormenor existente na pintura da obra em estudo).

Tabela 5: Classificação dos critérios de avaliação enumerados de 1 a 10.

\begin{tabular}{|c|c|c|c|}
\hline Questões & Imagem A & Imagem B & Imagem C \\
\hline \multirow{5}{*}{$\begin{array}{l}\text { 1. Presença de sobreposições/ repintes } \\
\text { na imagem }\end{array}$} & Má: 3 & Má: 3 & Má: 3 \\
\hline & Aceitável: 1 & Aceitável & Aceitável \\
\hline & Boa & Boa & Boa: 1 \\
\hline & Muito Boa & Muito Boa: 1 & Muito Boa \\
\hline & Não sei/Não se aplica & Não sei/Não se aplica & Não sei/Não se aplica \\
\hline \multirow{5}{*}{$\begin{array}{l}\text { 2. Existência de desenho } \\
\text { subjacente }\end{array}$} & Má: 2 & Má: 2 & Má: 4 \\
\hline & Aceitável & Aceitável: 1 & Aceitável \\
\hline & Boa: 2 & Boa: 1 & Boa \\
\hline & Muito Boa & Muito Boa & Muito Boa \\
\hline & Não sei/Não se aplica & Não sei/Não se aplica & Não sei/Não se aplica \\
\hline \multirow{5}{*}{$\begin{array}{l}\text { 3. Adequação da escala de cinzentos } \\
\text { para o estudo em causa }\end{array}$} & Má & Má: 1 & Má: 2 \\
\hline & Aceitável & Aceitável: 1 & Aceitável \\
\hline & Boa: 2 & Boa: 1 & Boa: 1 \\
\hline & Muito Boa: 1 & Muito Boa: 1 & Muito Boa \\
\hline & Não sei/Não se aplica & Não sei/Não se aplica & Não sei/Não se aplica: 1 \\
\hline \multirow{5}{*}{$\begin{array}{l}\text { 4. Nitidez dos contornos de todas as } \\
\text { estruturas que compóem a imagem }\end{array}$} & Má & Má & Má: 1 \\
\hline & Aceitável & Aceitável: 1 & Aceitável \\
\hline & Boa: 2 & Boa: 2 & Boa: 2 \\
\hline & Muito Boa: 2 & Muito Boa: 1 & Muito Boa: 1 \\
\hline & Não sei/Não se aplica & Não sei/Não se aplica & Não sei/Não se aplica \\
\hline \multirow{5}{*}{ 5.A dequação da relação sinal-ruído } & Má & Má: 2 & Má: 1 \\
\hline & Aceitável: 2 & Aceitável & Aceitável \\
\hline & Boa: 2 & Boa: 2 & Boa \\
\hline & Muito Boa & Muito Boa & Muito Boa: 3 \\
\hline & Não sei/Não se aplica & Não sei/Não se aplica & Não sei/Não se aplica \\
\hline \multirow{5}{*}{$\begin{array}{l}\text { 6. Pinceladas diferentes na imagem/ } \\
\text { Processo criativo e técnico na tela }\end{array}$} & Má: 1 & Má & Má: 3 \\
\hline & Aceitável & Aceitável & Aceitável \\
\hline & Boa: 1 & Boa: 3 & Boa: 1 \\
\hline & Muito Boa: 2 & Muito Boa: 1 & Muito Boa \\
\hline & Não sei/Não se aplica & Não sei/Não se aplica & Não sei/Não se aplica \\
\hline \multirow{5}{*}{ 7. Existência de vários materiais } & Má: 2 & Má: 2 & Má: 2 \\
\hline & Aceitável & Aceitável & Aceitável \\
\hline & Boa & Boa & Boa \\
\hline & Muito Boa & Muito Boa & Muito Boa \\
\hline & Não sei/Não se aplica: 2 & Não sei/Não se aplica: 2 & Não sei/Não se aplica: 2 \\
\hline \multirow{4}{*}{ 8. Adequação da relação sinal-ruído } & Má & Má & Má: 1 \\
\hline & Aceitável: 1 & Aceitável: 4 & Aceitável: 2 \\
\hline & Boa: 1 & Boa & Boa: 1 \\
\hline & Muito Boa: 2 & Muito Boa & Muito Boa \\
\hline
\end{tabular}




\begin{tabular}{|c|c|c|c|}
\hline & Não sei/Não se aplica & Não sei/Não se aplica & Não sei/Não se aplica \\
\hline \multirow{5}{*}{$\begin{array}{l}\text { 9. Adequação do contraste } \\
\text { da imagem }\end{array}$} & Má & Má & Má: 1 \\
\hline & Aceitável: 1 & Aceitável: 1 & Aceitável: 1 \\
\hline & Boa: 2 & Boa: 3 & Boa \\
\hline & Muito Boa: 1 & Muito Boa & Muito Boa: 1 \\
\hline & Não sei/Não se aplica & Não sei/Não se aplica & Não sei/Não se aplica \\
\hline \multirow{5}{*}{ 10. Nitidez da imagem/ figura } & Má & Má: 1 & Má: 1 \\
\hline & Aceitável & Aceitável: 1 & Aceitável: 1 \\
\hline & Boa: 4 & Boa & Boa \\
\hline & Muito Boa & Muito Boa: 2 & Muito Boa: 2 \\
\hline & Não sei/Não se aplica & Não sei/Não se aplica & Não sei/Não se aplica \\
\hline
\end{tabular}

Conjunto III (Figura 5 A-C): Representa o canto inferior direito da pintura 1B.

Na categoria "visualização de sobreposições/repintes", dois observadores referiram não os observar e os restantes indicarem que este critério não se aplica a este conjunto. Para a avaliação da existência de "desenho subjacente" as respostas foram iguais. Quanto às categorias de avaliação "pinceladas/processo criativo", "existência de vários materiais", "adequação da escala de cinzentos", "nitidez dos contornos" e "nitidez da figura" a imagem mais pontuada foi a imagem 5B (Sistema 2).
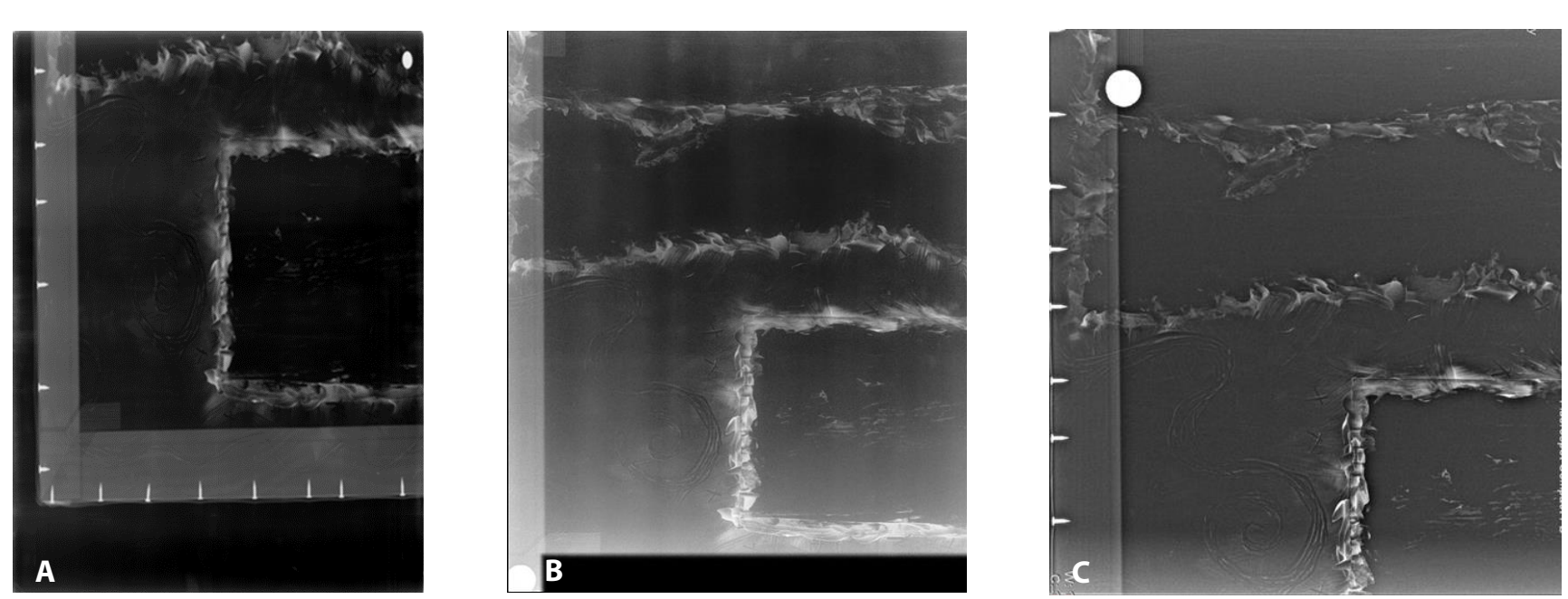

Quanto às categorias "conservação do suporte/grade" e "relação sinal-ruído" foi a imagem $5 \mathrm{~A}$ (Sistema 3) que mostrou dar mais resposta. Os comentários deixados pelos observadores vão de encontro aos diferentes materiais que compõe a pintura bem como o modo de fixação da grade (madeira fixada com pregos, fixação mais antiga).

Estas avaliações são passíveis de serem comprovadas na tabela 6.

Figura 5: Sistema 3/equipamento industrial (A); Sistema 2/CR (B); Sistema 1/DR (C).

Tabela 6: Classificação dos critérios de avaliação enumerados de 1 a 9 e comentários dos observadores.

\begin{tabular}{|c|c|c|c|}
\hline Questões & Imagem A & Imagem B & Imagem C \\
\hline \multirow{5}{*}{$\begin{array}{l}\text { 1. Presença de sobreposiçōes/ repintes } \\
\text { na imagem }\end{array}$} & Má: 2 & Má: 2 & Má: 2 \\
\hline & Aceitável & Aceitável & Aceitável \\
\hline & Boa & Boa & Boa \\
\hline & Muito Boa & Muito Boa & Muito Boa \\
\hline & Não sei/Năo se aplica: 2 & Não sei/Não se aplica: 2 & Não sei/Não se aplica: 2 \\
\hline \multirow{5}{*}{$\begin{array}{l}\text { 2. Existência de desenho } \\
\text { subjacente }\end{array}$} & Má: 2 & Má: 2 & Má: 2 \\
\hline & Aceitável & Aceitável & Aceitável \\
\hline & Boa & Boa & Boa \\
\hline & Muito Boa & Muito Boa & Muito Boa \\
\hline & Não sei/Não se aplica: 2 & Não sei/Não se aplica: 2 & Não sei/Não se aplica: 2 \\
\hline \multirow{2}{*}{$\begin{array}{l}\text { 3. Adequação da escala de cinzentos } \\
\text { para o estudo em causa }\end{array}$} & Má & Má & Má: 1 \\
\hline & Aceitável: 1 & Aceitável & Aceitável \\
\hline
\end{tabular}




\begin{tabular}{|c|c|c|c|}
\hline & Boa: 1 & Boa: 1 & Boa \\
\hline & Muito Boa: 2 & Muito Boa: 3 & Muito Boa: 3 \\
\hline & Não sei/Não se aplica & Não sei/Não se aplica & Não sei/Não se aplica: 1 \\
\hline \multirow{5}{*}{ 4. Existência de vários materiais } & Má & Má & Má: 1 \\
\hline & Aceitável: 1 & Aceitável & Aceitável \\
\hline & Boa: 2 & Boa: 1 & Boa \\
\hline & Muito Boa: 1 & Muito Boa: 3 & Muito Boa: 3 \\
\hline & Não sei/Não se aplica & Não sei/Não se aplica: 3 & Não sei/Não se aplica: 3 \\
\hline \multirow{5}{*}{$\begin{array}{l}\text { 5. Adequação da escala de cinzentos } \\
\text { para o estudo em causa }\end{array}$} & Má & Má & Má \\
\hline & Aceitável: 3 & Aceitável & Aceitável: 1 \\
\hline & Boa & Boa: 2 & Boa: 2 \\
\hline & Muito Boa: 1 & Muito Boa: 2 & Muito Boa: 1 \\
\hline & Não sei/Não se aplica & Não sei/Não se aplica & Não sei/Não se aplica: 1 \\
\hline \multirow{5}{*}{$\begin{array}{l}\text { 6. Nitidez dos contornos de todas as } \\
\text { estruturas que compóem a imagem }\end{array}$} & Má & Má & Má: 1 \\
\hline & Aceitável & Aceitável & Aceitável: 1 \\
\hline & Boa: 2 & Boa: 3 & Boa \\
\hline & Muito Boa: 2 & Muito Boa: 1 & Muito Boa: 3 \\
\hline & Não sei/Não se aplica & Não sei/Não se aplica & Não sei/Não se aplica \\
\hline \multirow{5}{*}{$\begin{array}{l}\text { 7. Adequação do contraste } \\
\text { da imagem }\end{array}$} & Má & Má & Má \\
\hline & Aceitável: 2 & Aceitável & Aceitável: 1 \\
\hline & Boa: 1 & Boa: 4 & Boa \\
\hline & Muito Boa: 1 & Muito Boa & Muito Boa: 3 \\
\hline & Não sei/Não se aplica & Não sei/Não se aplica & Não sei/Não se aplica \\
\hline \multirow{5}{*}{ 8. Adequação da relação sinal-ruído } & Má & Má & Má: 1 \\
\hline & Aceitável & Aceitável: 1 & Aceitável: 2 \\
\hline & Boa: 3 & Boa: 3 & Boa \\
\hline & Muito Boa: 1 & Muito Boa & Muito Boa: 1 \\
\hline & Não sei/Não se aplica & Não sei/Não se aplica & Não sei/Não se aplica \\
\hline \multirow{5}{*}{ 9. Nitidez da imagem/ figura } & Má & Má & Má: 1 \\
\hline & Aceitável: 1 & Aceitável & Aceitável: 1 \\
\hline & Boa: 2 & Boa: 3 & Boa \\
\hline & Muito Boa: 1 & Muito Boa: 1 & Muito Boa: 2 \\
\hline & Não sei/Não se aplica & Não sei/Não se aplica & Não sei/Não se aplica \\
\hline \multirow{2}{*}{$\begin{array}{l}\text { 10.Observação de outros } \\
\text { achados/comentários }\end{array}$} & \multicolumn{3}{|c|}{ Sim } \\
\hline & \multicolumn{3}{|c|}{ Não } \\
\hline Comentários & \multicolumn{3}{|c|}{$\begin{array}{l}\text { Neste conjunto os comentários vão de encontro aos diferentes materiais que compõe a pintura bem como c } \\
\text { modo de fixação da grade (madeira fixada com pregos, fixação mais antiga). }\end{array}$} \\
\hline
\end{tabular}

Conjunto IV (Figura 6 A-C): Representa o canto inferior esquerdo da pintura $1 \mathrm{~B}$.

Para esta sequência de imagens um observador referiu haver "sobreposições/repintes", enquanto para os restantes estes não foram visíveis, bem como a presença de "desenho subjacente". Quanto à visualização de "pinceladas/processo criativo" foi a imagem 6C (Sistema 2) que obteve as respostas mais favoráveis. Nas categorias "existência de vários materiais", "adequação da escala de cinzentos", "adequação do contraste" $e$ "nitidez da figura" foi a imagem 6A (Sistema 1), a mais pontuada.

Quanto ao estado de "conservação do suporte/grade" foi a imagem 6B (Sistema 3) que se destacou na pontuação. Relativamente à "nitidez dos contornos" as imagens $6 \mathrm{~A}$ (Sistema 1) e 6B (Sistema 3) dividem simetricamente os observadores, mas quanto à "relação sinal-ruído" a imagem 6B (Sistema 3) foi a mais pontuada. Estas avaliações encontram-se descritas na tabela 7. 

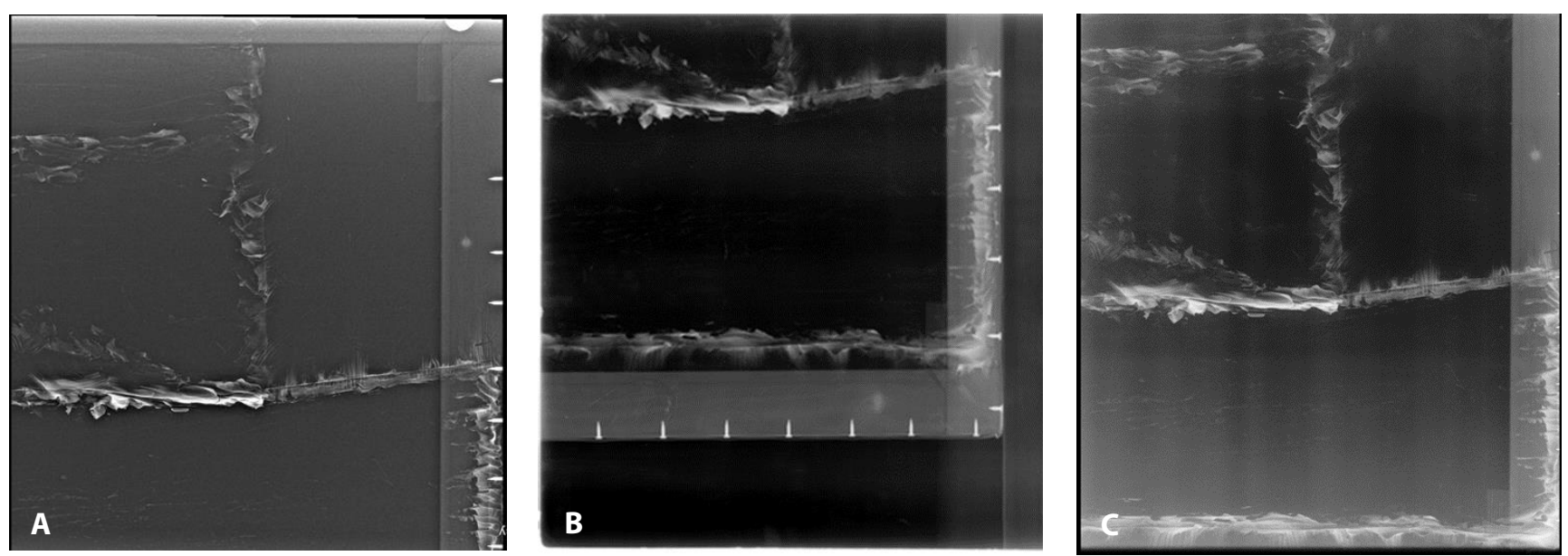

Figura 6: Sistema 1/DR (A); Sistema 3/equipamento industrial (B); Sistema 2/CR (C).

Tabela 7: Classificação dos critérios de avaliação enumerados de 1 a 10.

\begin{tabular}{|c|c|c|c|}
\hline Questões & Imagem A & Imagem B & Imagem C \\
\hline \multirow{5}{*}{$\begin{array}{l}\text { 1. Presença de sobreposiçōes/ repintes } \\
\text { na imagem }\end{array}$} & Má: 2 & Má: 3 & Má: 2 \\
\hline & Aceitável & Aceitável & Aceitável: 1 \\
\hline & Boa: 1 & Boa & Boa: 1 \\
\hline & Muito Boa & Muito Boa & Muito Boa \\
\hline & Não sei/Não se aplica: 1 & Não sei/Não se aplica: 1 & Não sei/Não se aplica: 1 \\
\hline \multirow{5}{*}{$\begin{array}{l}\text { 2. Existência de desenho } \\
\text { subjacente }\end{array}$} & Má: 2 & Má: 2 & Má: 4 \\
\hline & Aceitável & Aceitável & Aceitável \\
\hline & Boa & Boa & Boa \\
\hline & Muito Boa & Muito Boa & Muito Boa \\
\hline & Não sei/Não se aplica: 2 & Não sei/Não se aplica & Não sei/Não se aplica: 2 \\
\hline \multirow{5}{*}{$\begin{array}{l}\text { 3. Pinceladas diferentes na imagem/ } \\
\text { Processo criativo e técnico na tela }\end{array}$} & Má: 1 & Má & Má \\
\hline & Aceitável & Aceitável: 2 & Aceitável: 1 \\
\hline & Boa: 2 & Boa: 2 & Boa: 2 \\
\hline & Muito Boa: 1 & Muito Boa & Muito Boa: 1 \\
\hline & Não sei/Não se aplica & Não sei/Não se aplica & Não sei/Não se aplica \\
\hline \multirow{5}{*}{ 4. Existência de vários materiais } & Má & Má: 1 & Má \\
\hline & Aceitável & Aceitável & Aceitável \\
\hline & Boa & Boa: 2 & Boa: 1 \\
\hline & Muito Boa: 3 & Muito Boa & Muito Boa: 1 \\
\hline & Não sei/Não se aplica: 1 & Não sei/Não se aplica: 1 & Não sei/Não se aplica: 2 \\
\hline \multirow{5}{*}{$\begin{array}{l}\text { 5. Adequação da escala de cinzentos } \\
\text { para o estudo em causa }\end{array}$} & Má & Má: 1 & Má \\
\hline & Aceitável & Aceitável: 1 & Aceitável \\
\hline & Boa & Boa: 2 & Boa: 3 \\
\hline & Muito Boa: 4 & Muito Boa & Muito Boa: 1 \\
\hline & Não sei/Não se aplica & Não sei/Não se aplica & Não sei/Não se aplica \\
\hline \multirow{5}{*}{ 6. Adequação do contraste da imagem } & Má & Má & Má: 1 \\
\hline & Aceitável: 1 & Aceitável: 2 & Aceitável \\
\hline & Boa: 2 & Boa & Boa: 3 \\
\hline & Muito Boa: 1 & Muito Boa: 2 & Muito Boa \\
\hline & Não sei/Não se aplica & Não sei/Não se aplica & Não sei/Não se aplica \\
\hline \multirow{5}{*}{ 7.Nitidez da imagem/ figura } & Má: 1 & Má & Má: 1 \\
\hline & Aceitável & Aceitável: 2 & Aceitável \\
\hline & Boa & Boa: 2 & Boa: 3 \\
\hline & Muito Boa: 3 & Muito Boa & Muito Boa \\
\hline & Não sei/Não se aplica & Não sei/Não se aplica & Não sei/Não se aplica \\
\hline
\end{tabular}




\begin{tabular}{|c|c|c|c|}
\hline \multirow{5}{*}{$\begin{array}{l}\text { 8. Perceção do estado de conservação } \\
\text { do suporte/grade }\end{array}$} & Má & Má & Má \\
\hline & Aceitável & Aceitável & Aceitável \\
\hline & Boa & Boa: 1 & Boa \\
\hline & Muito Boa: 2 & Muito Boa: 2 & Muito Boa: 2 \\
\hline & Não sei/Não se aplica: 2 & Não sei/Não se aplica: 1 & Não sei/Não se aplica: 2 \\
\hline \multirow{5}{*}{$\begin{array}{l}\text { 9. Nitidez dos contornos de todas as } \\
\text { estruturas que compõem a imagem }\end{array}$} & Má & Má: 1 & Má \\
\hline & Aceitável: 1 & Aceitável: 1 & Aceitável: 1 \\
\hline & Boa: 1 & Boa: 1 & Boa: 2 \\
\hline & Muito Boa: 2 & Muito Boa: 1 & Muito Boa: 1 \\
\hline & Não sei/Não se aplica & Não sei/Não se aplica & Não sei/Não se aplica \\
\hline \multirow{5}{*}{ 10. Adequação da relação sinal-ruído } & Má: 1 & Má & Má: 1 \\
\hline & Aceitável: 1 & Aceitável & Aceitável: 1 \\
\hline & Boa & Boa: 2 & Boa: 2 \\
\hline & Muito Boa: 2 & Muito Boa: 2 & Muito Boa \\
\hline & Não sei/Não se aplica & Não sei/Não se aplica & Não sei/Não se aplica \\
\hline \multirow{2}{*}{$\begin{array}{l}\text { Observação de outros } \\
\text { achados/comentários }\end{array}$} & \multicolumn{3}{|c|}{ Sim } \\
\hline & \multicolumn{3}{|c|}{ Não } \\
\hline
\end{tabular}

Conjunto V (Figura 7 A-C): Representa o centro da pintura 1C.

Quanto às categorias de análise presença de "repintes/ sobreposições", de "desenho subjacente", "pinceladas/ processo criativo", "existência de vários materiais",
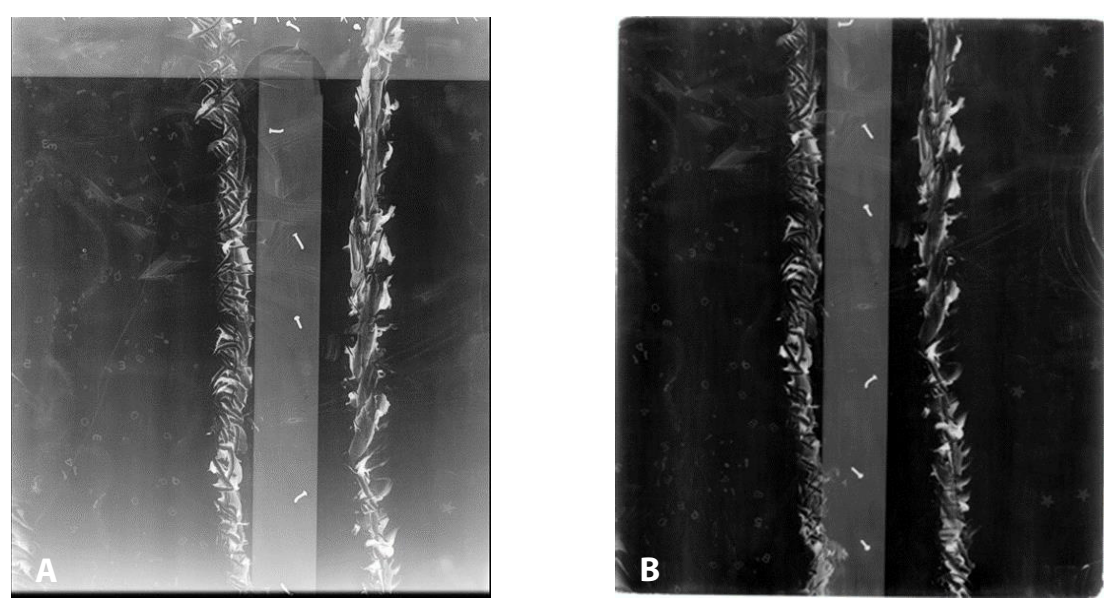

"adequação da escala de cinzentos", "nitidez dos contornos", "relação sinal-ruído", "contraste da imagem" e "nitidez da imagem/figura" foi a imagem 7A (Sistema 2) a mais pontuada, como é possível observar na tabela 8.

Figura 7: Sistema 2/CR (A); Sistema 3/equipamento industrial (B); Sistema 1/DR (C).

Tabela 8: Classificação dos critérios de avaliação enumerados de 1 a 10 .

\begin{tabular}{|c|c|c|c|}
\hline Questões & Imagem A & Imagem B & Imagem C \\
\hline \multirow{5}{*}{$\begin{array}{l}\text { 1. Presença de sobreposições/ repintes } \\
\text { na imagem }\end{array}$} & Má: 2 & Má: & Má: 3 \\
\hline & Aceitável & Aceitável: 2 & Aceitável \\
\hline & Boa & Boa & Boa \\
\hline & Muito Boa: 2 & Muito Boa & Muito Boa \\
\hline & Não sei/Não se aplica & Não sei/Não se aplica & Não sei/Não se aplica: 1 \\
\hline \multirow{5}{*}{$\begin{array}{l}\text { 2. Existência de desenho } \\
\text { subjacente }\end{array}$} & Má: 2 & Má: 3 & Má: 2 \\
\hline & Aceitável & Aceitável & Aceitável \\
\hline & Boa: 1 & Boa & Boa \\
\hline & Muito Boa & Muito Boa & Muito Boa \\
\hline & Não sei/Não se aplica: 1 & Não sei/Não se aplica: 1 & Não sei/Não se aplica: 2 \\
\hline
\end{tabular}


Artigos Científicos

\begin{tabular}{|c|c|c|c|}
\hline \multirow{5}{*}{$\begin{array}{l}\text { 3. Pinceladas diferentes na imagem/ } \\
\text { Processo criativo e técnico na tela }\end{array}$} & Má & Má: 1 & Má \\
\hline & Aceitável & Aceitável & Aceitável: 2 \\
\hline & Boa & Boa: 3 & Boa: 2 \\
\hline & Muito Boa: 4 & Muito Boa & Muito Boa \\
\hline & Não sei/Não se aplica & Não sei/Não se aplica & Não sei/Não se aplica \\
\hline \multirow{5}{*}{ 4. Existência de vários materiais } & Má & Má & Má: 1 \\
\hline & Aceitável & Aceitável: 2 & Aceitável: 2 \\
\hline & Boa: 1 & Boa: 2 & Boa: 1 \\
\hline & Muito Boa: 3 & Muito Boa & Muito Boa \\
\hline & Não sei/Não se aplica & Não sei/Não se aplica & Não sei/Não se aplica \\
\hline \multirow{5}{*}{$\begin{array}{l}\text { 5. Adequação da escala de cinzentos } \\
\text { para o estudo em causa }\end{array}$} & Má & Má: 1 & Má: 1 \\
\hline & Aceitável & Aceitável: 1 & Aceitável: 2 \\
\hline & Boa & Boa: 2 & Boa: 1 \\
\hline & Muito Boa: 4 & Muito Boa & Muito Boa \\
\hline & Não sei/Não se aplica & Não sei/Não se aplica & Não sei/Não se aplica \\
\hline \multirow{5}{*}{$\begin{array}{l}\text { 6. Nitidez dos contornos de todas as } \\
\text { estruturas que compõem a imagem }\end{array}$} & Má & Má & Má: 1 \\
\hline & Aceitável & Aceitável: 1 & Aceitável: 1 \\
\hline & Boa & Boa: 3 & Boa: 2 \\
\hline & Muito Boa: 4 & Muito Boa & Muito Boa: 1 \\
\hline & Não sei/Não se aplica & Não sei/Não se aplica & Não sei/Não se aplica \\
\hline \multirow{5}{*}{ 7. Adequação da relação sinal-ruído } & Má & Má: 1 & Má: 1 \\
\hline & Aceitável & Aceitável & Aceitável: 2 \\
\hline & Boa: 2 & Boa: 3 & Boa: 1 \\
\hline & Muito Boa: 2 & Muito Boa & Muito Boa \\
\hline & Não sei/Não se aplica & Não sei/Não se aplica & Não sei/Não se aplica \\
\hline \multirow{5}{*}{ 8. Adequação do contraste da imagem } & Má & Má & Má \\
\hline & Aceitável & Aceitável: 2 & Aceitável: 3 \\
\hline & Boa: 2 & Boa: 1 & Boa: 1 \\
\hline & Muito Boa: 2 & Muito Boa: 1 & Muito Boa \\
\hline & Não sei/Não se aplica & Não sei/Não se aplica & Não sei/Não se aplica \\
\hline \multirow{5}{*}{ 9. Nitidez da imagem/ figura } & Má & Má & Má \\
\hline & Aceitável & Aceitável: 1 & Aceitável: 2 \\
\hline & Boa: 1 & Boa: 3 & Boa \\
\hline & Muito Boa: 3 & Muito Boa & Muito Boa: 2 \\
\hline & Não sei/Não se aplica & Não sei/Não se aplica & Não sei/Não se aplica \\
\hline \multirow{2}{*}{$\begin{array}{l}\text { 10. Observação de outros achados/ } \\
\text { comentários }\end{array}$} & \multicolumn{3}{|c|}{ Sim } \\
\hline & \multicolumn{3}{|c|}{ Não } \\
\hline
\end{tabular}

Relativamente ao "estado de conservação da grade/ suporte" $50 \%$ respondeu "não se aplica" e sendo que os outros $50 \%$ referiram, haver boa visualização.

Conjunto VI (Figura 8 A-C): Representa o lado direito da pintura $1 \mathrm{C}$.

Nas categorias "presença de sobreposições/repintes" e "desenho subjacente", nesta composição de imagens, os observadores referiram que estes não eram visíveis. Quanto às "pinceladas/processo criativo", "conservação do suporte/ grade", "escala de cinzentos", "nitidez dos contornos" e "adequação do contraste" foi a imagem 8A (Sistema 3) que obteve melhor pontuação.

A imagem 8B (Sistema 2) foi mais pontuada nas categorias de "existência de vários materiais", "relação sinal-ruído" e "nitidez da figura". Todos estes resultados encontram-se presentes na tabela 9. 

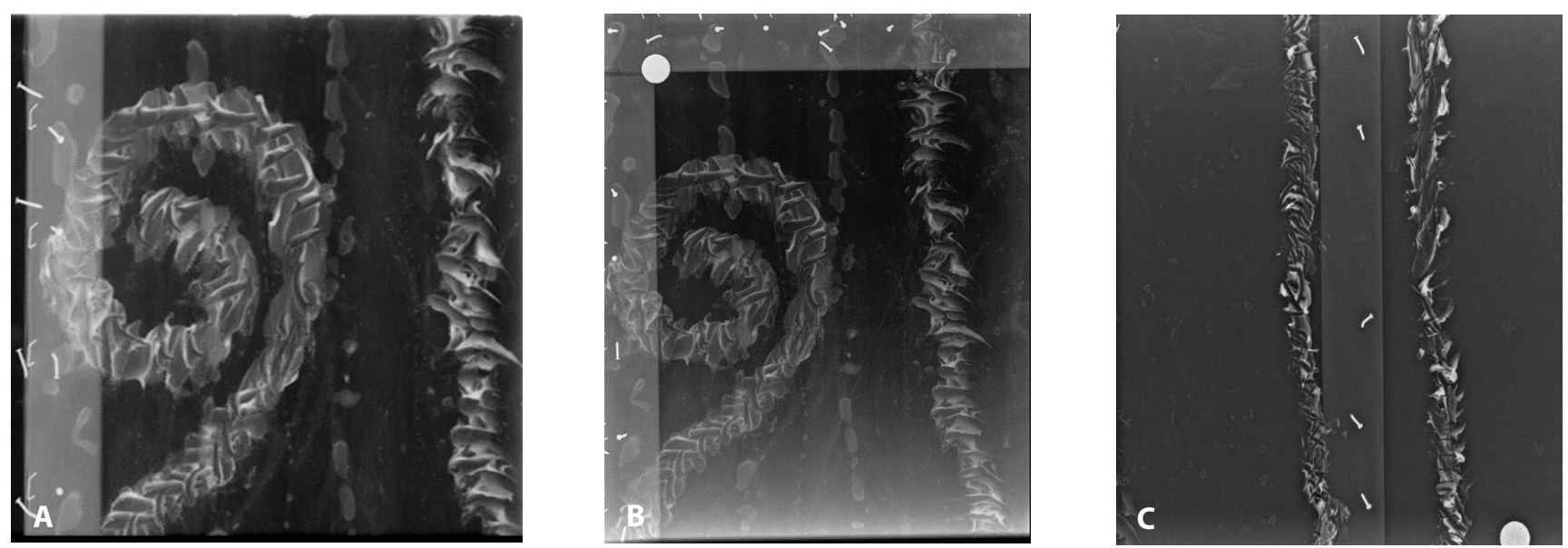

Figura 8: Sistema 3/equipamento industrial (A); Sistema 2/CR (B); Sistema 1/DR (C).

Tabela 9: Classificação dos critérios de avaliação enumerados do 1 ao 10.

\begin{tabular}{|c|c|c|c|}
\hline Questões & Imagem A & Imagem B & Imagem C \\
\hline \multirow{5}{*}{$\begin{array}{l}\text { 1. Presença de sobreposiçōes/ repintes } \\
\text { na imagem }\end{array}$} & Má: 2 & Má: 2 & Má: 2 \\
\hline & Aceitável & Aceitável & Aceitável \\
\hline & Boa & Boa & Boa \\
\hline & Muito Boa & Muito Boa & Muito Boa \\
\hline & Não sei/Não se aplica: 2 & Não sei/Não se aplica: 2 & Não sei/Não se aplica: 2 \\
\hline \multirow{5}{*}{$\begin{array}{l}\text { 2. Existência de desenho } \\
\text { subjacente }\end{array}$} & Má: 2 & Má: 2 & Má: 2 \\
\hline & Aceitável & Aceitável & Aceitável \\
\hline & Boa & Boa & Boa \\
\hline & Muito Boa & Muito Boa & Muito Boa \\
\hline & Não sei/Não se aplica: 2 & Não sei/Não se aplica: 2 & Não sei/Não se aplica: 2 \\
\hline \multirow{5}{*}{$\begin{array}{l}\text { 3. Pinceladas diferentes na imagem/ } \\
\text { Processo criativo e técnico na tela }\end{array}$} & Má & Má & Má: 1 \\
\hline & Aceitável & Aceitável: 1 & Aceitável: 2 \\
\hline & Boa: 1 & Boa: 2 & Boa \\
\hline & Muito Boa: 3 & Muito Boa: 1 & Muito Boa: 1 \\
\hline & Não sei/Não se aplica & Não sei/Não se aplica & Não sei/Não se aplica \\
\hline \multirow{5}{*}{$\begin{array}{l}\text { 4. Perceção do estado de conservação } \\
\text { do suporte/grade }\end{array}$} & Má & Má & Má \\
\hline & Aceitável & Aceitável & Aceitável \\
\hline & Boa & Boa: 1 & Boa: 1 \\
\hline & Muito Boa: 3 & Muito Boa: 2 & Muito Boa: 1 \\
\hline & Não sei/Não se aplica: 1 & Não sei/Não se aplica: 1 & Não sei/Não se aplica: 2 \\
\hline \multirow{5}{*}{$\begin{array}{l}\text { 5. Adequação da escala de cinzentos } \\
\text { para o estudo em causa }\end{array}$} & Má & Má: 1 & Má: 1 \\
\hline & Aceitável & Aceitável & Aceitável: 1 \\
\hline & Boa: 3 & Boa: 2 & Boa \\
\hline & Muito Boa: 1 & Muito Boa: 1 & Muito Boa: 2 \\
\hline & Não sei/Não se aplica & Não sei/Não se aplica & Não sei/Não se aplica \\
\hline \multirow{5}{*}{$\begin{array}{l}\text { 6. Nitidez dos contornos de todas as } \\
\text { estruturas que compöem a imagem }\end{array}$} & Má & Má & Má \\
\hline & Aceitável: 1 & Aceitável: 2 & Aceitável: 1 \\
\hline & Boa: 2 & Boa & Boa: 1 \\
\hline & Muito Boa: 1 & Muito Boa: 2 & Muito Boa: 2 \\
\hline & Não sei/Não se aplica & Não sei/Não se aplica & Não sei/Não se aplica \\
\hline \multirow{5}{*}{ 7. Adequação do contraste da imagem } & Má & Má & Má: 2 \\
\hline & Aceitável & Aceitável & Aceitável: 1 \\
\hline & Boa: 1 & Boa: 3 & Boa: 1 \\
\hline & Muito Boa: 3 & Muito Boa: 1 & Muito Boa \\
\hline & Não sei/Não se aplica & Não sei/Não se aplica & Não sei/Não se aplica \\
\hline
\end{tabular}




\begin{tabular}{|c|c|c|c|}
\hline \multirow{5}{*}{ 8. Existência de vários materiais } & Má & Má & Má: 1 \\
\hline & Aceitável: 1 & Aceitável & Aceitável: 1 \\
\hline & Boa: 1 & Boa: 3 & Boa \\
\hline & Muito Boa: 2 & Muito Boa: 1 & Muito Boa: 2 \\
\hline & Não sei/Não se aplica & Não sei/Não se aplica & Não sei/Não se aplica \\
\hline \multirow{5}{*}{ 9. Adequação da relação sinal-ruído } & Má & Má & Má: 2 \\
\hline & Aceitável: 1 & Aceitável & Aceitável \\
\hline & Boa: 2 & Boa: 4 & Boa \\
\hline & Muito Boa: 1 & Muito Boa & Muito Boa: 2 \\
\hline & Não sei/Não se aplica & Não sei/Não se aplica & Não sei/Não se aplica \\
\hline \multirow{5}{*}{ 10. Nitidez da imagem/ figura } & Má & Má & Má: 1 \\
\hline & Aceitável: 1 & Aceitável & Aceitável: 2 \\
\hline & Boa: 1 & Boa: 2 & Boa: 1 \\
\hline & Muito Boa: 2 & Muito Boa: 2 & Muito Boa \\
\hline & Não sei/Não se aplica & Não sei/Não se aplica & Não sei/Não se aplica \\
\hline \multirow{2}{*}{$\begin{array}{l}\text { 11. Observação de outros } \\
\text { achados/comentários }\end{array}$} & & Sim & \\
\hline & & Não & \\
\hline
\end{tabular}

Conjunto VII (Figura 9 A-C): Representa o lado esquerdo da pintura 1C.

Não foi referida a presença de "repintes/sobreposições" e de "desenho subjacente". A imagem 9A (Sistema 1) foi a mais pontuada nas seguintes categorias: "existência de vários materiais", "adequação da escala de cinzentos", "nitidez dos contornos" e "nitidez da figura".
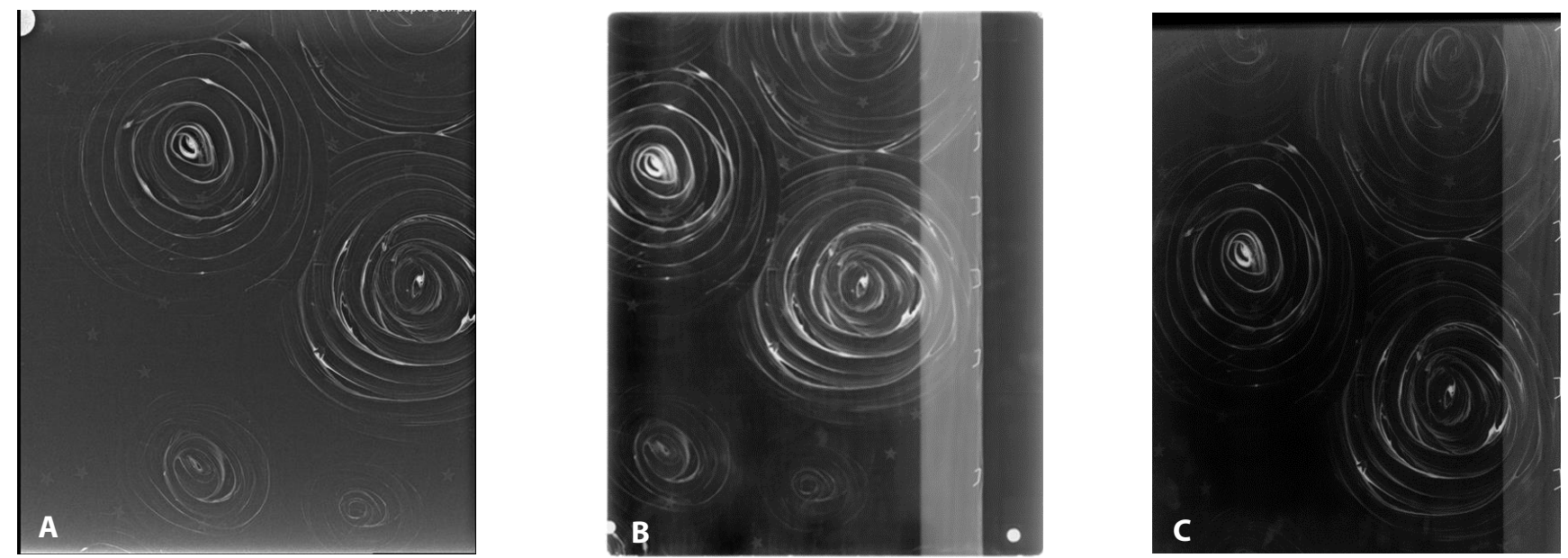

Figura 9: Sistema 1/DR (A); Sistema 3/equipamento industrial (B); Sistema 2/CR (C).

Tabela 10: Classificação dos critérios de avaliação enumerados de 1 a 8 .

\begin{tabular}{|c|c|c|c|}
\hline \multirow{2}{*}{ Questões } & Imagem A & Imagem B & Imagem C \\
\hline \multirow{4}{*}{ 1. Existência de vários materiais } & Má & Má & Má \\
\cline { 2 - 4 } & Aceitável & Aceitável: 1 & Aceitável: 3 \\
\cline { 2 - 4 } & Boa: 2 & Boa: 1 & Boa: 1 \\
\cline { 2 - 4 } & Muito Boa: 2 & Muito Boa: 2 & Muito Boa \\
\hline \multirow{3}{*}{$\begin{array}{c}\text { 2. Adequação da escala de cinzentos } \\
\text { para o estudo em causa }\end{array}$} & Não sei/Não se aplica & Não sei/Não se aplica & Má: 2 \\
\cline { 2 - 4 } & Má: 1 & Aceitável & Aceitável: 2 \\
\cline { 2 - 4 } & Aceitável & Boa: 3 & Boa aplica \\
\hline
\end{tabular}




\begin{tabular}{|c|c|c|c|}
\hline & Muito Boa: 2 & Muito Boa: 1 & Muito Boa \\
\hline & Não sei/Não se aplica & Não sei/Não se aplica & Não sei/Não se aplica \\
\hline \multirow{5}{*}{$\begin{array}{l}\text { 3. Nitidez dos contornos de todas as } \\
\text { estruturas que compóem a imagem }\end{array}$} & Má & Má & Má: 1 \\
\hline & Aceitável & Aceitável: 2 & Aceitável: 1 \\
\hline & Boa: 2 & Boa: 1 & Boa: 2 \\
\hline & Muito Boa: 2 & Muito Boa: 1 & Muito Boa \\
\hline & Não sei/Não se aplica & Não sei/Não se aplica & Não sei/Não se aplica \\
\hline \multirow{5}{*}{ 4. Nitidez da imagem/ figura } & Má & Má & Má: 2 \\
\hline & Aceitável: 1 & Aceitável: 1 & Aceitável: 1 \\
\hline & Boa & Boa: 3 & Boa: 1 \\
\hline & Muito Boa: 3 & Muito Boa & Muito Boa \\
\hline & Não sei/Não se aplica & Não sei/Não se aplica & Não sei/Não se aplica \\
\hline \multirow{5}{*}{$\begin{array}{l}\text { 5. Pinceladas diferentes na imagem/ } \\
\text { Processo criativo e técnico na tela }\end{array}$} & Má & Má & Má: 1 \\
\hline & Aceitável: 2 & Aceitável & Aceitável: 3 \\
\hline & Boa: 1 & Boa: 3 & Boa \\
\hline & Muito Boa: 1 & Muito Boa: 1 & Muito Boa \\
\hline & Não sei/Não se aplica & Não sei/Não se aplica & Não sei/Não se aplica \\
\hline \multirow{5}{*}{$\begin{array}{l}\text { 6. Perceção do estado de conservação } \\
\text { do suporte/grade }\end{array}$} & Má & Má & Má \\
\hline & Aceitável & Aceitável & Aceitável \\
\hline & Boa: 1 & Boa: 1 & Boa \\
\hline & Muito Boa: 1 & Muito Boa: 2 & Muito Boa: 3 \\
\hline & Não sei/Não se aplica: 2 & Não sei/Não se aplica: 1 & Não sei/Não se aplica: 1 \\
\hline \multirow{5}{*}{ 7. Adequação da relação sinal-ruído } & Má: 1 & Má & Má: 1 \\
\hline & Aceitável: 1 & Aceitável: 3 & Aceitável \\
\hline & Boa & Boa: 1 & Boa: 2 \\
\hline & Muito Boa: 2 & Muito Boa & Muito Boa: 1 \\
\hline & Não sei/Não se aplica & Não sei/Não se aplica & Não sei/Não se aplica \\
\hline \multirow{5}{*}{ 8. Adequação do contraste da imagem } & Má & Má & Má: 1 \\
\hline & Aceitável & Aceitável & Aceitável: 3 \\
\hline & Boa: 1 & Boa: 3 & Boa \\
\hline & Muito Boa: 3 & Muito Boa: 1 & Muito Boa \\
\hline & Não sei/Não se aplica & Não sei/Não se aplica & Não sei/Não se aplica \\
\hline \multirow{2}{*}{$\begin{array}{l}\text { 9. Observação de outros } \\
\text { achados/comentários }\end{array}$} & \multicolumn{3}{|c|}{ Sim } \\
\hline & \multicolumn{3}{|c|}{ Não } \\
\hline
\end{tabular}

\section{DISCUSSÃO E CONCLUSÕES}

Em resposta aos objetivos deste estudo que consistiu em analisar uma possível aplicabilidade, à pintura, dos sistemas de Radiologia de Tecnologia Digital (CR e DR), utilizados na clínica, foi possível observar que muitas classificações são semelhantes, mesmo pertencendo a conjuntos diferentes. Este facto indica a qualidade de imagem que os três Sistemas em análise fornecem, levando a que o observador classifique do mesmo modo imagens diferentes.

Nos três Sistemas que radiografaram as telas, tanto o Sistema 1 como o Sistema 2 são Sistemas que não foram desenvolvidos para o estudo de pinturas. Já o Sistema 3 é composto por uma ampola industrial específica para este fim.

O Sistema 2 consegue em alguns critérios de avaliação um valor de moda igual ao critério de classificação "Boa", sendo que em algumas categorias é mesmo classificada como "Muito Boa".

Com frequência, as imagens adquiridas no Sistema 3 vieram complementar as restantes imagens obtidas. Por exemplo: as radiografias adquiridas com este Sistema permitem observar o estado do suporte (tela) e na pintura $1 \mathrm{~A}$ fornecem detalhe do cabelo que não é visível em mais nenhuma radiografia de outros Sistemas. Apesar das radiografias obtidas por este Sistema não terem sido as mais pontuadas pelos observadores, permite complementar o estudo por ser um equipamento diretamente adaptado à investigação de obras de arte em geral, não só de pintura, mas também de escultura, ourivesaria, têxteis, etc., sendo a primeira escolha a nível nacional para as investigações mais importantes em curso na área artística.

Salienta-se que entre o Sistema 1 e o Sistema 2, é o Sistema 2 que, segundo a análise realizada pelos observadores, oferece resposta mais favorável às questões que foram colocadas na tabela de análise.

O Sistema 1 destacou-se do Sistema 2, na visualização de camadas de tinta subjacentes e na visualização das pinceladas de construção do processo criativo. No entanto, de um modo geral, em caso de opção única entre o Sistema 1 e 2, como o melhor para realizar a análise de pinturas por radiografia, foi o Sistema 2 o eleito. 
Na área da Saúde observa-se que o digital (que utiliza baixas energias) tem vindo a ganhar espaço e relevo na área da aquisição de imagem, mas como a aquisição digital por conversão indireta se aproxima mais da aquisição realizada em equipamento industriais (utiliza um maior tempo de exposição), provavelmente esta é uma das razões que levou a que o sistema 2 fosse o selecionado.

A título de curiosidade e de complemento do estudo, na imagem radiológica da pintura $1 \mathrm{~A}$ é possível demonstrar de forma clara as pinceladas do rosto, uma vez que para preencher a mancha do desenho, foi utilizada tinta branco de chumbo. Esta tinta é composta por elementos químicos de elevado número atómico e quando ocorre a interação com a radiação $X$, afirma-se em zonas hiperdensas, criando, de forma mais intensa, a diferenciação entre o branco e o preto na imagem radiológica.

Verificou-se com este estudo que é possível, com ligeiras adaptações, aplicar os métodos da Radiologia clínica ao estudo da pintura. A otimização do processo passa pelo aumento dos parâmetros de exposição técnica, nomeadamente a tensão ( $k V p)$ o tempo de aquisição (s) e a intensidade da corrente $(\mathrm{mAs})$. Enquanto estes parâmetros têm de ser baixos na área da saúde, devido aos seus efeitos biológicos, na pintura podem ser mais elevados proporcionando um maior contraste na imagem final. Destaca-se que no Sistema industrial o tempo de aquisição atingia os 5 minutos enquanto na Radiologia clínica o tempo é cerca de 4 vezes inferiores.

As principais limitações deste estudo são o número reduzido de obras de arte, porém se fossem mais numerosas produziriam mais de 21 imagens tornando-se exaustivo para os classificadores.

Não foi aplicado qualquer coeficiente de inter-correlação para avaliar a concordância inter ou intra observador dado que na pintura a observação e subsequente categorização aplica todos os sentidos, sem destaque para o sentido da visão, a fim de obter uma determinada informação. Podemos, desta forma, perceber e apreender os aspetos do real, do bonito e do belo de um modo que seja relevante em função de determinado propósito científico.

Como indicação para futuros estudos seria importante ampliar o número dos recursos metodológicos utilizados: pinturas, sistemas e observadores. Um estudo mais alargado seria o desejável. Embora os estudos refiram que, a radiação $x$, é inofensiva para a obra, (Janssen et al., 2016; Oliveira-Davi F et al., 2013), seria também importante pesquisar, à semelhança dos efeitos danosos da radiação $\mathrm{X}$ nos meios biológicos, qual o efeito que esta quando transportada por um feixe de fotões $X$, de elevado poder de penetração e energia, induz na pintura (Pessanha-Sofia et al., 2008).

A investigação das habilidades de observação e leitura entre radiologistas e especialistas em Arte pode constituir um desafio e contribuir para a confiabilidade dos estudos desta natureza que recorrem a metodologias de observação. A identificação de pigmentos em pinturas, manuscritos, papéis de parede ou outros êxitos artísticos, são essenciais na datação, autenticação, conservação e restauração. No mundo da arte, o uso de uma técnica não destrutiva, nesses estudos é fundamental mas poderá ser repensada a sua combinação alternada com o método termográfico, por ser este último ser mais seguro para o operador e não requerer qualquer certificação ou precauções especiais para o público (Gavrilov-D. et al., 2014).

$\mathrm{O}$ aparecimento de novos e diferentes equipamentos de baixo custo é outra promessa importante na aplicação aos estudos artísticos. (Consentino-Antonino, 2020).

Os sistemas avaliados obtiveram valores de pontuação que nos indicam a sua praticável utilização na aplicação às obras de arte. Os sistemas radiológicos clínicos, com detetores de conversão indireta ou direta de diferentes energias e fotodetetores do sinal elétrico, apresentam hoje significativas melhorias nos padrões imagiológicos alargando assim as suas possibilidades de aplicação.

\section{Agradecimentos}

Um agradecimento reconhecido a todos os que forneceram obras para a realização deste estudo e a todas as instituições que o acolheram e apoiaram: Departamento de Imagiologia do Hospital do SAMS na pessoa de Dr. João Paulo Costa e ao Laboratório José de Figueiredo nas pessoas Dr.a Gabriela Carvalho e Técnico Luís Piorro. Realça-se e agradece-se também os préstimos dos observadores pela observação e classificação das imagens.

\section{REFERÊNCIAS BIBLIOGRÁFICAS}

Cruz-João A. O início da radiografia de obras de arte em Portugal e a relação entre a radiografia, a conservação e a política. Conservar Património 11:13-32, 2010.

Cruz-João A. Do certo ao incerto: o estudo laboratorial e os materiais do políptico de S. Vicente. Nuno Gonçalves, Novos Documentos Estudo da Pintura Portuguesa do Século XV:41-5, 1994.

Cruz-João A. A matéria de que é feita a arte. Contribuições para o estudo da pintura portuguesa. Boletim da Sociedade Portuguesa de Química 84:39-44, 2002.

Cruz-João A. Imagens Perdidas, Imagens Achadas: Pinturas Reveladas pelos Raios X no Instituto José de Figueiredo. Centenário da Descoberta dos Raios X: 32-33, 1995.

Fleming-Stuart. Art Forgery: Some Scientific Defenses. Proceedings of the American Philosophical Society, JSTOR 130: 175-195, 1986.

Dewing-Thomas W, Hobbs S, Cheng Y, Olin JS. A Look Beneath the Surface. American Art 4:63-85, 1990.

Alves-Rita. A importância da peritagem e avaliação para os seguros de obras de arte. ISCTE Business School- Instituto Universitário de Lisboa, Lisboa, 2013.

Oliveira-Davi F, Calza C, Rocha HS, Nascimento JR, Lopes RT. Application of digital radiography in the analysis of cultural heritage. International Nuclear Atlantic Conference - INAC, Recife, PE, Brazil, November 24-29: 2013.

Marinković-Slobodan, Stošić-Opinćal T, Tomić O. Radiology and fine art. American Journal of Roentgenology 199:24-26, 2012.

Calza-Cristiane, Oliveira DF, Rocha HS, Pedreira A, Lopes RT. Analysis of the painting "Gioventú" (Eliseu Visconti) using EDXRF and computed radiography. Applied Radiation and Isotopes 68: 861$865,2010$.

James-A. Everette, Gibbs SJ, Sloan M, Price RR. Erickson JJ. Digital Radiography in the Analysis of Paintings: A New and Promising Technique. Journal of the American Institute for Conservation 22: 41-48, 1982

Gavrilov-D., Maev R.Gr., Almond D.P. A review of imaging methods in analysis of works of art: Thermographic imaging method in art analysis. Canadian Journal of Physics 92: 341-364, 2014

Emandi-loan, loeva M, Duliu OG, Emandi A. X-ray radiographic study of some panel painting icons from the beginning of the XXth 


\section{Artigos Científicos}

century. International Journal of Conservation Science 2: 179-183, 2011.

Kenzo-Toishi. Radiography of the Great Buddha at Kamakura. Studies in Conservation, 10: 47-52, 1965.

Siemens: Multix Select -DR. Data Sheet First Time, First Choice, 2014

Leblans-Paul, Vandenbroucke D, Willems P. Storage Phosphors for Medical Imaging. Materials 4: 1034-1086, 2011.

Consentino-Antonino. Low-cost X-Radiography for Art. Disponível em: https://chsopensource.org/low-cost-x-radiography-for-paintings/, consultado em 18-10-2020, 2020

Pessanha-Sofia, Guilherme A, Manso M, Gil M, Mendes J, Cruz A, Candeias A, Mirão J, Costa M, Carvalho ML. Pigment Identification on Artworks by EDXRF. Bridging Scince with Art Colours, Évora, 54: 2008.

Salgueiro-Joana, Carvalho S. Radiografia in situ do Pentecostes do mosteiro de Santa Cruz de Coimbra: estudo técnico do suporte e sua relevância na história da conservação e restauro da pintura sobre madeira em Portugal. Estudos de Conservação e Restauro 1: 113-127, 2009.

Salgueiro-Joana, Pessoa J, Pessoa GP. Estudo técnico do suporte dos painéis do retábulo-mor da Sé de Lamego de Grão Vasco: processo e interpretação da radiografia. Estudos de Conservação e Restauro 2:110-123, 2010.

Alba-Laura, Celis MJ. Niños Jugando a los dados de Pedro Núñez de Villavicencio: Historia de una obra a través de su radiografía. Geconservación 0:47-61, 2009.

Museo del Prado. Niños jugando a los dados. Disponível em: https:/www.museodelprado.es/coleccion/obra-de-arte/nios-jugando-alos-dados/73e7ebe4-733b-4fe1-8bbd-430fd5b7f9e8?searchMeta=ninos $\% 20$ jugand, consultado em 08-04-2020, 2019.

Spring-Marika, Higgitt C, Saunders D. Investigation of Pigment-Medium Interaction Process in Oil Paint containing Degraded Smalt. National Gallery Technical Bulletin 26: 56-70, 2005.

Cruz-João A. A radiografia no Laboratório para o Exame das Obras de Arte, do Museu Nacional de Arte Antiga (1936-1965). 100 Anos da Descoberta dos Raios X. A Radiação X no Desenvolvimento Científico e na Sociedade: 61-62, 1995.

Património Cultural-Direção Geral do Património Cultural. Apontamentos para a História da Conservação e Restauro em Portugal. Disponível em: http://www.patrimoniocultural.gov. $\mathrm{pt} / \mathrm{pt} /$ patrimonio/conservacao-e-restauro-laboratorio-josede-figueiredo/apontamentos-para-historia-da-conservacao-erestauro-em-portugal/, consultado em 08-04-2020, 2019.

Siemens. Multix Select DR. Disponível em: http://medfau.com/wpcontent/uploads/2017/12/Multix-Select-DR_Data.pdf, consultado em 08-04-2020, 2014.

Padfield- Joseph, Saunders D, Cupitt J, Atkinson R. Improvements in the Acquisition and Processing of X-Ray Images of Paintings. National Gallery Technical Bulletin 23 :62-75, 2002.

Oliveira-Davi F, Calza C, Rocha HS, Nascimento JR, Lopes RT. Application of digital radiography in the analysis of cultural heritage. International Nuclear Atlantic Conference: 24-29,2013.

Siemens. MULTIX PRO / TOP, VERTIX Solitaire, VERTIX PRO / TOP. Modular X-ray systems for radiographic applications. 2010.

YXLON. Y.SMART 160E 0.4/1.5 Portable X-Ray System.

Ludewig- Eberhard, Richter A, Frame M. Diagnostic imaging - Evaluating image quality using visual grading characteristic (VGC) analysis. Veterinary Research Communications 34: 473-479, 2010.

Art Intitute Chicago. Conservation and Science. Disponível em: http://www.artic.edu/collections/conservation/revealing-picassoconservation-project/examinationtechniques/x-radiography, consultado em 09-04-2020.

Ween-Borgny, Jakobsen JA. Sharpness and noise in digital chest radiographs, assessed by visual rating. Radiography Open 2:30-50, 2015.
Tingberg-Anders, Herrmann C, Besjakov J, Rodenacker K, Almén A, Sund $P$, Mattsson S, Mansson LG. Evaluation of lumbar spine images with added pathology. Proceedings of SPIE-The International Society for Optical Engineering 3981: 34-42, 2000. 